This document is confidential and is proprietary to the American Chemical Society and its authors. Do not copy or disclose without written permission. If you have received this item in error, notify the sender and delete all copies.

\title{
Influence of length and charge on the activity of a-helical amphipathic antimicrobial peptides
}

\begin{tabular}{|r|l|}
\hline Journal: & Biochemistry \\
\hline Manuscript ID & bi-2016-01071d.R1 \\
\hline Manuscript Type: & Article \\
\hline Date Submitted by the Author: & n/a \\
\hline Complete List of Authors: & $\begin{array}{l}\text { Gagnon, Marie-Claude; Universite Laval, Departement de Chimie } \\
\text { Strandberg, Erik; Karlsruhe Institute of Technology, Institute of Biological } \\
\text { Interfaces (IBG-2) } \\
\text { Grau-Campistany, Ariadna; University of Barcelona, Faculty of Chemistry, } \\
\text { Department of Organic Chemistry } \\
\text { Wadhwani, Parvesh; Karlsruhe Institute of Technology, Institute for } \\
\text { Biological Interfaces, IBG-2 } \\
\text { Reichert, Johannes; KIT, Institute of Biological Interfaces (IBG-2) } \\
\text { Bürck, Jochen; Karlsruhe Institute of Technology (KIT), Institute of } \\
\text { Biological Interfaces (IBG-2) } \\
\text { Rabanal, Francesc; University of Barcelona, Organic Chemistry } \\
\text { Auger, Michèle; Université Laval, Quebec, Département de Chimie } \\
\text { Paquin, Jean-François; Université Laval, Département de chimie } \\
\text { Ulrich, Anne; KIT, Inst. Org. Chem.; KIT, Institute of Biological Interfaces } \\
\text { (IBG-2) }\end{array}$ \\
\hline
\end{tabular}

\section{SCHOLARONE \\ Manuscripts}




\title{
Influence of length and charge on the activity of $\alpha$-helical amphipathic antimicrobial peptides
}

\author{
Marie-Claude Gagnon ${ }^{1,2}$, Erik Strandberg ${ }^{3}$, Ariadna Grau-Campistany ${ }^{4}$, Parvesh Wadhwani ${ }^{3}$, \\ Johannes Reichert ${ }^{3}$, Jochen Bürck ${ }^{3}$, Francesc Rabanal ${ }^{4}$, Michèle Auger ${ }^{2}$, Jean-François Paquin ${ }^{1}$, \\ Anne S. Ulrich ${ }^{3,5, *}$ \\ ${ }^{1}$ Department of Chemistry, PROTEO, CGCC, 1045 avenue de la Médecine, Université Laval, \\ Québec, Canada, G1V 0A6; ${ }^{2}$ Department of Chemistry, PROTEO, CERMA, CQMF, 1045 \\ avenue de la Médecine, Université Laval, Québec, Canada, G1V 0A6; ${ }^{3}$ Karlsruhe Institute of \\ Technology (KIT), Institute of Biological Interfaces (IBG-2), POB 3640, 76021 Karlsruhe, \\ Germany; ${ }^{4}$ Secció de Química Orgànica, Departament de Química Inorgànica i Orgànica, \\ Facultat de Química, Universitat de Barcelona, Barcelona, Spain; ${ }^{5}$ KIT, Institute of Organic \\ Chemistry, Fritz-Haber-Weg 6, 76131 Karlsruhe, Germany.
}

\section{Corresponding Author}

*E-mail: anne.ulrich@kit.edu. Telephone: +49-(0)721-608-23222. Fax: +49-(0)721-608-24823.

\section{Funding}

This work was supported by FRQNT (MCG, JFP, MA), PROTEO (MCG, JFP, MA), the Canada Research Chair Program (JFP), and Université Laval (JFP, MA), Deutscher Akademischer Austauschdienst (DAAD, scholarship A/12/77249 to AGC), and EMBO (short-term fellowship ASTF 530-2012 to AGC).

\section{Notes}

The authors declare no competing financial interest. 


\section{ABBREVIATIONS}

AMPs, antimicrobial peptides;

ANTS, 8-amino-naphtalene-1,3,6-trisulfonic acid sodium salt;

$\mathrm{CD}$, circular dichroism spectroscopy;

DErPC, 1,2-dierucoyl-sn-glycero-3-phosphatidylcholine;

DErPG, 1,2-dierucoyl-sn-glycero-3-phosphatidylglycerol;

DMoPC, 1,2-dimyristoleoyl-sn-glycero-3-phosphatidylcholine;

DMoPG, 1,2-dimyristoleoyl-sn-glycero-3-phosphatidylglycerol;

DMPC, 1,2-dimyristoyl-sn-glycero-3-phosphatidylcholine;

DMPG, 1,2-dimyristoyl-sn-glycero-3-phosphatidylglycerol;

DPX, $p$-xylene-bis(N-pyridinium)bromide;

Lyso-MPC, 1-myristoyl-2-hydroxy-sn-glycero-3-phosphatidylcholine;

MIC, minimal inhibitory concentration;

PB, phosphate buffer;

$\mathrm{P} / \mathrm{L}$, peptide-to-lipid molar ratio;

POPC, 1-palmitoyl-2-oleoyl-sn-glycero-3-phosphatidylcholine;

POPG, 1-palmitoyl-2-oleoyl-sn-glycero-3-phosphatidylglycerol;

Rhod-PE, 1,2-dioleoyl-sn-glycero-3-phosphoethanolamine-N-(lissamine rhodamine B sulfonyl). 


\begin{abstract}
Hydrophobic mismatch is important for pore-forming amphipathic antimicrobial peptides, as demonstrated recently [Grau-Campistany et al., 2015, Sci. Rep. 5, 9388]. A series of different length peptides had been generated with the heptameric repeat sequence KIAGKIA, called KIA peptides, and it was found that only those helices long enough to span the hydrophobic thickness of the membrane could induce leakage in lipid vesicles, and there was also a clear lengthdependence in the antimicrobial and hemolytic activities. For the original KIA sequences the cationic charge increased with peptide length. The goal in the present paper is to examine whether the charge also has an effect on activity, hence we constructed two further series of peptides with a similar sequence as the KIA peptides, but with a constant charge of +7 for all lengths from 14 to 28 amino acids. For both of these new series, a clear length-dependence similar to that for KIA peptides was observed, indicating that charge has only a minor influence. Both series also showed a distinct threshold length for peptides to be active, which correlates directly with the thickness of the membrane. Amongst the longer peptides, the new series showed only slightly lower activities than the original KIA peptides of the same length that had a higher charge. Shorter peptides, in which Gly was replaced with Lys, showed similar activities as KIA peptides of the same length, but peptides in which Ile was replaced by Lys lost their helicity and were less active.
\end{abstract}

Keywords: Hydrophobic (mis)matching; antimicrobial peptides; amphiphilic $\alpha$-helices; lengthdependent antibiotic/hemolytic/leakage activity; transmembrane pores; helix orientation in lipid bilayers; biological membrane thickness 
Natural antimicrobial peptides (AMPs) are ubiquitous molecules involved in the immune system of almost all species, such as bacteria, insects, plants, and mammals, in order to prevent invasion of pathogens. ${ }^{1-3}$ Beyond their efficiency against both Gram-positive and Gram-negative bacteria, some peptides are also documented to be active against viruses, fungi and cancer cells. ${ }^{4-6}$ Despite their efficiency and wide range of action, these peptides often show toxicity against mammalian cells and/or pharmacokinetic and pharmacodynamic issues. ${ }^{7,8}$ Therefore, the interest toward the design of improved synthetic AMPs has grown over the last few decades, and there has been much efforts to better understand the importance of molecular determinants on their activity and their mechanisms of action. ${ }^{6,9,10}$ Antimicrobial peptides often share common characteristics, such as a cationic charge, a marked amphiphilicity, and a primary sequence of 12 to 45 amino acids. ${ }^{11}$ Concerning their secondary structure, they can be classified in four major categories: $\alpha$-helix, $\beta$ sheet, extended and loop. Most common are $\alpha$-helical or $\beta$-sheet structures, and especially the group of cationic amphiphilic $\alpha$-helical AMPs have been intensely studied. ${ }^{12-14}$

Features derived from natural AMP sequences are widely applied in the development of newly designed peptides. For instance, the design of MSI-103, ${ }^{15}$ a synthetic amphipathic $\alpha$-helical peptide, was based on the sequence of PGLa, a natural AMP isolated from the skin of the African frog Xenopus laevis. ${ }^{16}$ MSI-103 is a 21-mer peptide (sequence [KIAGKIA] ${ }_{3}-\mathrm{NH}_{2}$ ) characterized by a global charge of +7 and a high activity against bacteria. ${ }^{15,17}$ This peptide was shown to be more active against bacteria and at the same time less hemolytic than PGLa, indicating a higher selectivity toward prokaryotic cells and a better therapeutic index. ${ }^{15,18}$

For several linear cationic $\alpha$-helical peptides, including PGLa, relevant insights obtained from various biophysical studies suggest that the antimicrobial activity occurs via a pore formation mechanism, involving permeabilization of the lipid membrane. ${ }^{19-26}$ According to the standard Shai-Huang-Matsuzaki-model, ${ }^{27-29}$ peptides first bind to the membrane by electrostatic interactions and form an amphipathic helix on the surface. At higher concentrations the peptides can get inserted, and at least some peptides get into a transmembrane pore-forming state. The most common pore models are barrel-stave pores, proposed for alamethicin, ${ }^{30}$ and toroidal pores, proposed for magainin, melittin and other peptides. ${ }^{27}$ The barrel-stave pores are formed by peptides lining the pore like staves in a barrel, and is most likely not valid for highly charged cationic peptides like MSI-103, which are more likely to form toroidal pores, where lipid head groups together with peptides line the interior of the pore. 
In general, the antimicrobial activity of peptides can depend on several molecular determinants, such as length, charge, amphiphilicity, hydrophobicity and hydrophobic moment. ${ }^{9,10}$ To better characterize the mechanism of action of MSI-103 by considering the hypothesis of pore formation, we have examined recently the influence of peptide length on the activity of new MSI-103 derivatives. ${ }^{31}$ Since pores are proposed to be enclosed by a ring of peptide helices that are aligned in a transmembrane state, ${ }^{9,27}$ the match between peptide length and lipid membrane thickness could be important and was therefore investigated systematically. A series of eight analogs of MSI-103 were synthesized, keeping the same primary repeat sequence, but varying the number of amino acids from 14 to 28 . All peptides were shown by circular dichroism to be largely $\alpha$-helical in the presence of membranes. Alluding to the repeat sequence [KIAGKIA], they were named KIAn, where $n$ represents the number of amino acids in the peptide sequence. The length of these amphiphilic helices can be estimated to vary between 21 and $42 \AA$, assuming a length of $1.5 \AA$ per residue for an ideal $\alpha$-helix. A clear length dependence was demonstrated, as a specific minimal length was necessary to observe antimicrobial activity. This threshold peptide length was directly correlated with the thickness of the lipid membranes in which it was active, as shown by fluorescence leakage experiments in vesicles with lipids having different acyl chain lengths. ${ }^{31}$

Due to the design of the original sequences, the different lengths of peptides in the KIA series simultaneously involved changes in the peptide charge, too. All peptides have an amidated C-terminus, one positive charge at the N-terminus and several positively charged Lys residues. Once the same cationic amino acid sequence is repeated, the longer peptides are more charged. While MSI-103 (KIA21) has a charge of +7 , the shortest peptide of the series (KIA14) contains only 5 positive charges, whereas the longest one (KIA28) has a +9 charge. In fact, it is known that the total charge is a key factor in the activity of $\alpha$-helical peptides. ${ }^{10,32,33}$ Since electrostatic interactions are of primary importance in the binding of these peptides to the membrane surface, they are partially responsible for their selectivity toward prokaryotic cells. Even though no simple correlation could be determined between charge and peptide activity, several trends have been reported. ${ }^{34}$ Previous studies have shown that antifungal activity ${ }^{35}$ or antimicrobial potency ${ }^{10,15,36-}$ 38 of peptides was significantly enhanced by an increase in their total cationic charge. Other studies have shown evidence that an optimal number of charges exists, with more or less specific distribution. In these cases, the binding affinity for negatively charged lipid membranes was too 
weak for peptides with a low cationic charge. On the other hand, beyond a certain threshold, peptides with a high cationic charge were less active, due to the instability of the pores formed, and they were less selective toward bacterial membranes. ${ }^{39-41}$ Therefore, in our previous study, the activity of KIA peptides may well have been influenced by the number of charges rather than exclusively by the length of the peptides.

In order to confirm the length-dependent activity of KIA analogs and to dissect its effect on the pore formation mechanism from other factors such as charge, we have now designed two new series of peptides. They are analogs of the KIA series, but their primary sequences were slightly modified to maintain a global charge +7 on each peptide, which is the same as for KIA2 1 (MSI-103), the origin of the series. Thus, the hypothesis of a length-dependence can now be studied independently of charge effects. Our strategy for the first series of analogs, called KIA(7) peptides, relies on keeping the same amino acid types as in the KIA series. Therefore, only the same set of amino acids as in the original MSI-103 sequence was used for the substitutions. For the shorter peptides Ile was replaced by Lys to increase the charge, and for the longer ones Lys was replaced by Ala to reduce the charge. The second series of analogs, called KIXA peptides, was based on adding new amino acid types to keep a similar global polarity as for KIA peptides. For the shorter peptides Gly was replaced by Lys, and for the longer ones Lys was replaced by Ser. ( $\mathrm{X}$ in KIXA is the new amino acid compared to the original KIA peptide, hence KIKAn is the name of the shorter peptides and KISAn of the longer ones). Helical wheels of the shortest and the longest peptide of the two new series are illustrated in Figure 1, together with wheels for the original KIA peptides of the same lengths. The helical wheels of all peptides are very similar, with a similar distribution of amino acids. The polar sector is somewhat shifted in the short KIA(7) and KIKA peptides compared to KIA, while for the longer peptides the polar sector is identical for all three series.

Here, we describe a study of those two new series of peptides analogs with different lengths, derived from the original MSI-103. To evaluate their biological activity, antimicrobial and hemolytic assays were performed with living cells, and fluorescence leakage experiments were carried out systematically with synthetic phospholipid bilayers of controlled composition, which allowed the evaluation of hydrophobic length effects by using different membrane thicknesses. In addition, we used solid-state ${ }^{15} \mathrm{~N}-\mathrm{NMR}$ spectroscopy to study the peptide 
orientation in various lipid membranes, in order to provide structural data related to the pore formation hypothesis.

\section{MATERIALS AND METHODS}

\section{Materials}

Fmoc-protected amino acids and reagents for peptide synthesis were purchased from Merck Biosciences (Darmstadt, Germany) and/or Iris Biotech (Marktretwitz, Germany). ${ }^{15} \mathrm{~N}$ labelled alanine was obtained from Cambridge Isotope Laboratories (Andover, MA, USA) and was Fmoc-protected using Fmoc-Cl as previously described. ${ }^{42}$ Solvents for peptide synthesis were from Merck (Darmstadt, Germany) or from Biosolve (Valkenswaard, Netherlands) and solvents for high-pressure liquid chromatography (HPLC) purification were obtained from Fischer Scientific (Geel, Belgium). The lipids 1,2-dimyristoyl-sn-glycero-3-phosphatidylcholine (DMPC), 1,2-dimyristoyl-sn-glycero-3-phosphatidylglycerol (DMPG), 1,2-dimyristoleoyl-snglycero-3-phosphatidylcholine (DMoPC), 1,2-dimyristoleoyl-sn-glycero-3-phosphatidylglycerol (DMoPG), 1-palmitoyl-2-oleoyl-sn-glycero-3-phosphatidylcholine (POPC), 1-palmitoyl-2oleoyl-sn-glycero-3-phosphatidylglycerol (POPG), 1-palmitoyl-2-oleoyl-sn-glycero-3phosphatidylethanolamine (POPE), 1-myristoyl-2-hydroxy-sn-glycero-3-phosphatidylcholine (lyso-MPC), and 1,2-dioleoyl-sn-glycero-3-phosphoethanolamine-N-(lissamine rhodamine B sulfonyl) (Rhod-PE) were obtained from Avanti Polar Lipids (Alabaster, USA); 1,2-dierucoyl-snglycero-3-phosphatidylcholine (DErPC) and 1,2-dierucoyl-sn-glycero-3-phosphatidylglycerol (DErPG) were purchased from NOF Corporation (Grobbendonk, Belgium). The fluorescent probes 8-amino-naphtalene-1,3,6-trisulfonic acid sodium salt (ANTS) and $p$-xylene-bis(Npyridinium)bromide (DPX) were obtained from Invitrogen - Molecular Probes (Karlsruhe, Germany).

\section{Peptide synthesis}

KIA peptides were synthesized using standard Fmoc solid phase peptide synthesis (SPPS) protocols $^{43,44}$ on an automated Syro II multiple peptide synthesizer (MultiSynTech, Witten, Germany). The crude peptides were purified with reverse-phase HPLC on a JASCO instrument 
(Groß-Umstadt, Germany), using a preparative Vydac C18 column with gradients of solvents A (95\% water, $5 \%$ acetonitrile, $5 \mathrm{mM} \mathrm{HCl})$ and $\mathrm{B}(95 \%$ acetonitrile, $5 \%$ water, $5 \mathrm{mM} \mathrm{HCl})$. Peptide purity was checked using LC-MS, an analytical LC (Agilent Technologies; Waldbronn, Germany) coupled to an ESI mass spectrometer ( $\mu$ TOF Bruker Daltonics, Bremen, Germany), and all peptides were found to be $>95 \%$ pure.

\section{Circular dichroism spectroscopy (CD)}

Samples for circular dichroism anaylsis were prepared by co-solubilizing DMPC and DMPG $(3 / 1 \mathrm{~mol} / \mathrm{mol})$ in $\mathrm{CHCl}_{3} / \mathrm{MeOH} 1 / 1(\mathrm{v} / \mathrm{v})$. The organic solvents were removed by a flow nitrogen for 30-60 min, followed by $4 \mathrm{~h}$ drying under vacuum. Then, the lipid film formed was dispersed in phosphate buffer (PB, $10 \mathrm{mM}, \mathrm{pH} 7)$ and homogenized by vortexing $10 \mathrm{~min}$, followed by 10 freeze (liquid $\mathrm{N}_{2}$ )-thaw $\left(37^{\circ} \mathrm{C}\right.$ )-vortex cycles. Small unilamellar vesicles (SUVs) were generated by sonication for $16 \mathrm{~min}$ in a high-power ultrasonic bath with a beaker-shaped sonotrode (UTR 200, Hielscher, Germany). To prepare the final samples, an aliquot of the peptide stock solution $(1 \mathrm{mg} / \mathrm{mL})$ in distilled water was added to either pure $10 \mathrm{mM} \mathrm{PB}$, or to the DMPC/DMPG (3/1 molar ratio) SUV dispersion in $10 \mathrm{mM} \mathrm{PB}$. Typical peptide concentrations of the final samples in phosphate buffer were 34-60 $\mu \mathrm{M}$, and for the vesicle samples $25-27 \mu \mathrm{M}$, with a peptide-to-lipid molar ratio $(\mathrm{P} / \mathrm{L})$ between $1 / 55$ and $1 / 59$.

CD spectra were recorded on a J-815 JASCO spectropolarimeter (JASCO, Groß-Umstadt, Germany) between 260 and $185 \mathrm{~nm}$ at $0.1 \mathrm{~nm}$ intervals, using $1 \mathrm{~mm}$ quartz-glass cells (Suprasil; Hellma, Müllheim, Germany), as previously reported. ${ }^{45}$ For each sample and for the baseline (peptide-free sample reference), three repeat scans at a scan-rate of $10 \mathrm{~nm} / \mathrm{min}, 8 \mathrm{~s}$ response time, and $1 \mathrm{~nm}$ bandwidth were averaged. The peptides were measured at $25^{\circ} \mathrm{C}$ in $10 \mathrm{mM}$ sodium phosphate buffer ( $\mathrm{pH} 7.0)$, and at $30^{\circ} \mathrm{C}$ in the presence of DMPC/DMPG lipid vesicles, using a water-thermostated rectangular cell holder. After subtracting the baseline of the pure solvent or lipid matrix, $\mathrm{CD}$ data were processed with the adaptative smoothing method, which is part of the Jasco Spectra Analysis software. Finally, the spectra were converted to mean residue ellipticities based on the weighed-in peptide amount and the volume of the sample for concentration determination. A quantitative deconvolution of $\mathrm{CD}$ data to determine the relative contents of different secondary structure elements was performed as described previously. ${ }^{46-54}$

\section{Minimum inhibitory concentration assay}


Antimicrobial activity was measured by a standard minimal inhibitory concentration (MIC) assay, as previously described, ${ }^{45,55}$ carried out with Gram-positive Staphylococcus aureus (DSM 1104) and Enterococcus faecalis (DSM 2570), and with Gram-negative Escherichia coli (DSM 1103) and Pseudomonas aeruginosa (DSM 1117). Bacteria were grown in Müller-Hinton medium at $37{ }^{\circ} \mathrm{C}$ overnight. Microtiter plates (96 wells of $100 \mu \mathrm{L}$ ) were filled with $50 \mu \mathrm{L}$ of Müller-Hinton (MH) medium, and serial 2-fold dilutions of the peptides with concentrations from 256 to $2 \mu \mathrm{mol} / \mathrm{L}$ (1024 to $64 \mu \mathrm{mol} / \mathrm{L}$ for Enterococcus faecalis) were arranged in three columns for each peptide. The three final columns of each plate remained without peptide, so that the last one served as the negative control (not inoculated) and the other two as positive control (without peptide). $50 \mu \mathrm{L}$ of bacterial suspension $(\mathrm{OD}=0.2$ ) was added to each well (except for the last column of each plate) to give a final concentration of $10^{6} \mathrm{CFU} / \mathrm{mL}$. The plates were incubated at $37{ }^{\circ} \mathrm{C}$ for $22 \mathrm{~h}$. Then, $20 \mu \mathrm{L}$ of the redox indicator Resazurin $(0.2 \mathrm{mg} / \mathrm{mL})$ was added to each well, and the plates were incubated at $37{ }^{\circ} \mathrm{C}$ for $2 \mathrm{~h}$. The MIC value for each peptide in each strain was determined visually on the basis of the color at the lowest peptide concentration inhibiting bacterial growth.

\section{Hemolysis assay}

The hemolytic activity was examined in a serial 2-fold dilution assay, as previously described. ${ }^{18}$ Citrate phosphate dextrose-stabilized blood bags with erythrocyte suspensions from healthy donors were obtained from the blood bank of the local municipal hospital (Städtisches Klinikum, Karlsruhe, Germany). The erythrocytes were washed three times with buffer (Tris$\mathrm{HCl}, 172 \mathrm{mM}, \mathrm{pH}$ 7.6). Afterwards, they were transferred from the pellet to a clean tube with the same Tris buffer to be diluted 10-fold, giving the stock cell suspension. Each peptide was diluted in Tris buffer to reach a peptide concentration of $2048 \mu \mathrm{g} / \mathrm{mL}$, and serial 2-fold dilution in 1.5 $\mathrm{mL}$ tubes allowed to set up final concentrations of peptide from 512 to $4 \mu \mathrm{g} / \mathrm{mL}$. The erythrocytes stock solution was further diluted to $0.25 \%(\mathrm{v} / \mathrm{v})$. After pre-incubating for $5 \mathrm{~min}$ at $37{ }^{\circ} \mathrm{C}, 200 \mu \mathrm{L}$ of the diluted erythrocyte suspension was transferred to each peptide-containing tube. For each peptide, $0 \%$ hemolysis was set by adding the erythrocytes to Tris buffer without any peptide, while $100 \%$ hemolysis was triggered by adding $1 \%$ Triton X-100 in the same buffer. The samples were incubated at $37^{\circ} \mathrm{C}$ for $30 \mathrm{~min}$ with gentle shaking. The tubes were centrifuged at $13000 \mathrm{rpm}$ for $10 \mathrm{~min}$ to pellet the remaining intact cells, and the absorbance of the supernatant at $540 \mathrm{~nm}$ was recorded against the negative control. The percentage of lysis was then calculated relative to 
$100 \%$ lysis induced by Triton X-100. All experiments were performed in triplicated to ensure good reproducibility.

\section{Vesicle leakage assay}

Samples for fluorescence leakage experiments were prepared by entrapping the fluorophor ANTS and the quencher DPX within large unilamellar vesicles, as previously described. ${ }^{56,57}$ ANTS (12.5 mM) and DPX (45 mM) were mixed together in $50 \mathrm{mM} \mathrm{NaCl}$ and 10 $\mathrm{mM}$ HEPES ( $\mathrm{pH}$ 7.5) to prepare the buffer solution. Liposomes were prepared by co-dissolving PC/PG (1/1 mol/mol) lipid mixtures in $\mathrm{CHCl}_{3} / \mathrm{MeOH}(3 / 1 \mathrm{v} / \mathrm{v})$ in a falcon tube, together with 0.1 mol\% Rhod-PE, by which the lipid loss during vesicle preparation and purification could be quantified. The lipid mixture was then dried under nitrogen flow for 30-60 min, followed by vacuum overnight. Buffer solution was added to the falcon tube, and the lipid film was resuspended by vigorous vortexing, followed by 10 freeze (liquid $\mathrm{N}_{2}$ )-thaw $\left(37{ }^{\circ} \mathrm{C}\right)$-vortex cycles. ${ }^{58}$ Large unilamellar vesicles (LUVs) were obtained by 41-fold extrusion (Avanti Mini Extruder; Avanti Polar Lipids, Alabaster, AL) of the liposomes through a nuclepore polycarbonate membrane (pore size $100 \mathrm{~nm}$, Whatman - GE Healthcare Europe, Freiburg, Germany) at room temperature (for POPC/POPG, POPE/POPG, and DErPC/DErPG) or at $37{ }^{\circ} \mathrm{C}$ (for DMoPC/DMoPG). Unencapsulated ANTS and DPX were separated from entrapped material by gel filtration, using spin columns filled with Sephacryl 100-HR (Sigma-Aldrich, Taufkirchen, Germany) and initially equilibrated with an elution buffer (150 mM NaCl, $10 \mathrm{mM} \mathrm{HEPES,} \mathrm{pH}$ 7.5) that balances the internal vesicle osmolarity. This purification was done once a day (for POPC/POPG, POPE/POPG, and DErPC/DErPG), or before every measurement (for DMoPC/DMoPG).

Leakage of encapsulated ANTS was monitored by fluorescence dequenching of ANTS. ${ }^{59}$ Fluorescence measurements were performed in a thermostated cuvette with constant stirring at 30 ${ }^{\circ} \mathrm{C}$ in the same buffer as for gel filtration. A FluoroMax2 spectrofluorimeter (HORIBA Jobin Yvon, Unterhaching, Germany) was used, setting the ANTS emission to $510 \mathrm{~nm}$ (5 nm slit) and its excitation to $355 \mathrm{~nm}$ ( $5 \mathrm{~nm}$ slit). The exact volume of vesicle solution needed for a final lipid concentration of $100 \mu \mathrm{M}$ was calculated, based on the Rhodamine (Rhod-PE) maximum fluorescence intensity of the prepared vesicles in comparison to the initial vesicles (before extrusion and purification). The peptides were solubilized in water at a concentration of $300 \mu \mathrm{M}$ (stock solution). For a leakage experiment, vesicles were added to the cuvette containing the 
peptide at the $\mathrm{P} / \mathrm{L}$ ratio to be tested, and fluorescence was monitored for $10 \mathrm{~min}$. After $10 \mathrm{~min}$, 0.25 vol\% Triton X-100 was added to obtain the fluorescence value corresponding to $100 \%$ leakage. The level of $0 \%$ leakage corresponded to the fluorescence of the vesicles after $10 \mathrm{~min}$ in a reference sample without peptide.

\section{Solid-state NMR}

For the preparation of macroscopically oriented NMR samples, peptides and lipids were weighed out in separated tubes to obtain the desired $\mathrm{P} / \mathrm{L}$ ratio. Peptides and lipids were solubilized separately with methanol (300-400 $\mu \mathrm{L})$, chloroform (100-200 $\mu \mathrm{L})$ and milliQ-water (10-30 $\mu \mathrm{L})$, and then mixed together. After 1 min vortexing, the mixture was spread onto 24 thin glass-plates of dimensions $9 \mathrm{~mm} \times 7.5 \mathrm{~mm} \times 0.08 \mathrm{~mm}$ (Marienfeld Laboratory Glassware, Lauda-Königshofen, Germany). The plates were dried in air for 20-60 min and under vacuum overnight. Plates were stacked and placed into a hydration chamber with $96 \%$ relative humidity at $48{ }^{\circ} \mathrm{C}$ for $18-24 \mathrm{~h}$, before wrapping the stack in parafilm and plastic foil for the NMR measurements.

All solid-state NMR measurements were carried out on a Bruker Avance 500 or $600 \mathrm{MHz}$ spectrometer (Bruker Biospin, Karlsruhe, Germany) at $35{ }^{\circ} \mathrm{C}$, as previously reported. ${ }^{60-65}{ }^{31} \mathrm{P}$ NMR spectra were recorded using a Hahn echo sequence with phase cycling, ${ }^{66}$ in order to check the quality of the lipid alignment in the samples. ${ }^{1} \mathrm{H}-{ }^{15} \mathrm{~N}$ cross polarization experiments, using a CP-MOIST pulse sequence, ${ }^{67}$ were performed using a double-tuned probe with a low-E flat-coil resonator ( $3 \mathrm{~mm} \times 9 \mathrm{~mm}$ cross section), employing a ${ }^{1} \mathrm{H}$ and ${ }^{15} \mathrm{~N}$ radiofrequency field strength of $65 \mathrm{kHz}$ during the cross polarization, and $36 \mathrm{kHz}{ }^{1} \mathrm{H}$ SPINAL16 decoupling ${ }^{68}$ during acquisition. A mixing time of 500 or $1000 \mu \mathrm{s}$ was used, the acquisition time was $10 \mathrm{~ms}$, the recycle time $4 \mathrm{~s}$, and 5000-30000 scans were accumulated. The ${ }^{15} \mathrm{~N}$ chemical shift was referenced using the signal of an ammonium sulfate dry powder sample set to $26.8 \mathrm{ppm}$. The oriented membrane samples were positioned within the flat-coil probe such that the lipid bilayer normal was aligned parallel to the static magnetic field. 


\section{RESULTS}

\section{Peptide synthesis and characterization by CD}

The original series of nine KIA peptides, with lengths of 14 to 28 amino acids and varying charges from +5 to +9 , had been previously synthesized. ${ }^{31}$ Here, 14 new peptides were synthesized with a net charge on each peptide of +7 , as listed in Table 1. The new peptides are grouped into two series of 7 peptides, called KIA(7) and KIXA, again with lengths between 14 and 28 amino acids. Each new series naturally contains also the original KIA19 and KIA21 peptides, as they have a charge of +7 . All peptides were synthesized with a ${ }^{15} \mathrm{~N}$-label in the backbone amide of Ala-10 for solid-state ${ }^{15} \mathrm{~N}-\mathrm{NMR}$ analysis.

Circular dichroism spectroscopy (CD) was used to determine the secondary structure of the peptides in different environments. In phosphate buffer, all 14 peptides showed a random coil conformation (Figure $\mathbf{2 A}$ and $\mathbf{C}$ ), as also observed for all original KIA peptides. ${ }^{31}$ In small unilamellar DMPC/DMPG (3/1) vesicles, most peptides formed $\alpha$-helices, as also observed previously for the KIA series, ${ }^{31}$ except for KIA(7)14 that remained disordered (Figure 2B and D). The secondary structure composition was obtained from deconvolution of the CD spectra, as given in Supporting Information Table S1. KIA(7)14 shows only 2\% helix, KIA(7)15 and $\operatorname{KIA}(7) 17$ also had reduced helix percentages of $37 \%$ and $44 \%$, respectively, while all other peptides were highly helical with $62-95 \%$, similar to the results for the KIA peptides. ${ }^{31}$ In general, the longer peptides are more helical, as expected if 3-4 residues close to the termini of each peptide are not in a well-defined helical conformation.

\section{Antimicrobial assay}

To examine the biological activity of the peptides against living bacteria we performed MIC assays, based on the notion that the different bacterial strains have different membrane thicknesses and/or surface charge densities. The KIA(7) (Tables 2 and S2) and KIXA (Table 3 and S3) peptides were measured for this study under identical conditions within the two series, using the same bacterial strains and under as similar conditions as possible to the previous KIA study (Tables 4 and S4), but minor differences in the growth of bacteria cannot be avoided when experiments are performed on different occasions. Therefore, the KIA19 and KIA21 peptides, which are common for all three series, were included in the two new series and considered as controls. For these peptides, in the new and old MIC assay, the difference is never more than one 
dilution factor (a factor of 2), so we can assume that differences between the KIA, KIA(7) and KIXA peptides of the same length within a factor 2 are not significant, while differences of a factor 4 or more can be considered important.

In E. coli, all peptides from the three series of the same length behave similarly (within one dilution factor), except for KIA(7)17 which is much less active that KIA17 and KIKA17. The threshold length for activity is 17 amino acids for KIA and KIKA peptides, but it is 19 amino acids for KIA(7). In P. aeruginosa, the threshold length for the original KIA peptides to be active was 21 amino acids. For the other two series, the longer peptides with 22-28 amino acids are active, but less so than the corresponding KIA peptides. Here, the original KIA peptides carry more charges $(+8$ or +9$)$ than the new ones $(+7)$, which is likely to have an influence. In $S$. aureus, the threshold is again 21 amino acids for all three series, and there is not much difference in the activity, except that KIA(7)22 and KISA22 are considerably less active than KIA22. In $E$. faecalis, the $\operatorname{KIA(7)~series~shows~a~similar~activity~as~the~original~KIA~series~for~all~lengths,~and~}$ also for the KIXA peptides the threshold length for activity was 24 amino acids, but again the KISA26 peptide is less active than KIA26 or KIA(7)26.

For all three series of peptides, the MIC results thus show a distinct length dependence. Since all the $\operatorname{KIA}(7)$ and KIXA peptides have +7 charge, this underlying length-dependent effect is a genuine effect and not due to any charge dependence.

\section{Hemolysis assay}

Useful AMPs should be selectively active against microorganisms and should not affect eukaryotic cells. Therefore, for the two new series of peptides their activities against erythrocytes was studied with a hemolysis assay. The KIA(7) (Figure 3E-H) and KIXA (Figure 3I-L) peptides were measured for this study under similar conditions as the original KIA series (Figure 3A-D), but with a different batch of blood. Therefore, minor differences in results cannot be avoided, and again the KIA19 and KIA21 peptides were included and measured here as controls. The results are summarized in Table S5.

The results are similar for all three series of peptides. For lengths up to 19 amino acids, there is almost no hemolysis, even at a very high peptide concentration of $512 \mu \mathrm{g} / \mathrm{mL}$. For 21 and more amino acids, a high hemolytic activity is achieved in all series at high peptide concentration. KIA21 gave more hemolysis in the new assay than the previous KIA study, which illustrates the 
variation possible in these biological assays due to different batches of blood. KIA22 and $\mathrm{KIA}(7) 22$ are more active than KIA21, but KISA22 is less active. Also with regard to MIC, KISA22 showed a low activity. KIA(7) peptides with 24-28 amino acids showed higher activity at lower concentrations than the corresponding KIA and KISA peptides; at the highest concentration peptides with 24 and more amino acids gave $100 \%$ hemolysis.

Similar to the antimicrobial assays, a clear length dependence is observed for all three series, and no charge dependence can be seen.

\section{Vesicle leakage}

Fluorescence experiments were performed to evaluate the leakage induced by the new KIA(7) and KIXA peptides in the presence of different lipid vesicles. In order to measure the effect of the peptide length on their activity, three lipid systems with unsaturated acyl chains of different lengths were compared. Previously, KIA peptides have been studied in POPC/POPG (with 16:0-18:1 acyl chains) and DErPC/DErPG (with di-22:1 acyl chains). Here, DMoPC/DMoPG (with di-14:1 acyl chains) was additionally used to measure the effect on even shorter lipid chains. The results are illustrated in Figures 4, S1 and S2 and in Tables S6, S7 and S8.

In DMoPC/DMoPG, all KIXA peptides (including the short KIKA14 that was not active against bacteria or erythrocytes) showed $100 \%$ leakage even at a peptide-to-lipid ratio of $\mathrm{P} / \mathrm{L}=$ 1/55-59. In the $\operatorname{KIA}(7)$ series, $100 \%$ leakage was seen for peptides with 17 or more amino acids. However, $\operatorname{KIA}(7) 14$ was not active even at $\mathrm{P} / \mathrm{L}=1 / 15$, and $\mathrm{KIA}(7) 15$ was also much less active than KIKA15. These results may be attributed to the partially or largely non-helical structure of these two peptides, which indicates that they do not bind to the membrane. In POPC/POPG, peptides of all three series with 17 or more amino acids were all highly active, except for $\operatorname{KIA}(7) 17$ which is totally inactive (and also has a lower helicity). In DErPC/DErPG, with an even larger membrane thickness, only peptides with at least 24 amino acids gave some leakage, yet not full activity even at $\mathrm{P} / \mathrm{L}=1 / 14$. This tendency was observed for all three series, amongst which the KIA peptides were the most active.

In addition to PC/PG lipid systems, POPE/POPG (1/1) was also used, which is more similar to E. coli membranes. ${ }^{69}$ The amount of leakage is lower in POPE/POPG than in POPC/POPG at a given P/L, but the threshold length is the same (see Figures 4, S1 and S2 and in 
Tables S6, S7 and S8). At a high P/L of 1/12-15, only peptides with at least 17 amino acids are active (except $\mathrm{KIA}(7) 17$ which is also not active in POPC/POPG).

All three series showed more pronounced vesicle leakage for the longer peptides, but also a distinct correlation between the length of the peptide and the hydrophobic thickness of the lipid bilayers employed. Peptides could only induce leakage when they were long enough to span the hydrophobic part of the membrane. In vesicles prepared from the shortest lipids, all peptides were active, while for the thick membranes only the longest peptides could induce leakage. Once again, these results are similar for all three series of peptides, hence the observed trend shows a distinct length dependence and a clear absence of charge dependence.

\section{Solid-state NMR}

It is straightforward to estimate the helix tilt angle of $\alpha$-helical peptides in a lipid membrane using solid-state NMR. The approximate orientation can be determined by studying a macroscopically oriented sample of a ${ }^{15} \mathrm{~N}$-labelled peptide in the backbone using ${ }^{15} \mathrm{~N}-\mathrm{NMR}$ spectroscopy. ${ }^{63,70-72}$ Each of the KIA(7) and KIXA peptides was therefore labelled with a ${ }^{15} \mathrm{~N}-\mathrm{Ala}$ residue at position 10 , and ${ }^{15} \mathrm{~N}-\mathrm{NMR}$ experiments were performed on all peptides in the presence of various lipid bilayers and at different peptide-to-lipid ratios. ${ }^{31} \mathrm{P}-\mathrm{NMR}$ experiments were also performed before and after each ${ }^{15} \mathrm{~N}-\mathrm{NMR}$ experiment, in order to evaluate the lipid orientation percentage and the stability of the sample during the ${ }^{15} \mathrm{~N}-\mathrm{NMR}$ experiment. Perturbations could occur due to the presence of the peptide or as a consequence of sample dehydration during the long measurement times.

${ }^{15} \mathrm{~N}-\mathrm{NMR}$ was done in POPC/POPG (Figure 5A and B, Figure S3 and Figure S4) and in DMoPC/DMoPG (Figures 5C and D, Figures S5 and S6), where also leakage experiments were done, for all $\mathrm{KIA}(7)$ and KIXA peptides at a constant peptide-to-lipid mass ratio that is equivalent to $\mathrm{P} / \mathrm{L}=1 / 50$ for $\mathrm{KIA} 21$ (and thus corresponds to varying $\mathrm{P} / \mathrm{L}$ molar ratios for the other peptides from $1 / 41$ to $1 / 72$ ). In all cases a chemical shift around 90 ppm was observed, corresponding to a surface-aligned S-state (see Table S9). The only exception was KIA(7)14, which gave a chemical shift of $120 \mathrm{ppm}$ in all cases, which is the isotropic value. Since this peptide was not helical according to $\mathrm{CD}$ and probably did not bind to the membrane, this shift cannot be used to determine the helix orientation. KIA(7)15 gave a shift of $82 \mathrm{ppm}$ in POPC/POPG, but a shift around $105 \mathrm{ppm}$ in DMoPC/DMoPG. This peptide also showed a less helical CD spectrum, so the value of 105 ppm may also be due to non-helicity and should not be used to estimate the 
peptide tilt. KIA(7)28 gave - in addition to the signal peak around $90 \mathrm{ppm}$ - a powder pattern from unoriented sample with a peak around $145 \mathrm{ppm}$. This sample was prepared multiple times but it was never possible to get a high quality orientation (see ${ }^{31} \mathrm{P}-\mathrm{NMR}$ spectrum in Figure S5).

In DMPC vesicles, all three series of peptides were measured at a constant peptide-to-lipid mass ratio (i.e. at varying $\mathrm{P} / \mathrm{L}=1 / 41$ to $1 / 72$ ), (see Figures $\mathbf{5 E}$ and $\mathbf{F}, \mathbf{S 7}$ and S8, and Table S9). In almost all cases a chemical shift around 90-100 ppm was observed, indicating S-state peptides. KIA21 gave a ${ }^{15} \mathrm{~N}$ chemical shift around $130 \mathrm{ppm}$ indicating a T-state, but the peak was much broader than for the other peptides. KIA(7)14 gave also here a chemical shift of $128 \mathrm{ppm}$, and KIA(7)15 a chemical shift of 107 ppm, probably because these peptides were not helical.

Next, ${ }^{15}$ N-NMR measurements were performed with mixed DMPC/lyso-MPC (2/1) lipid membranes, which are much better suited than pure DMPC to accommodate a transmembrane pore. $^{63,72,73}$ Again, the two series of peptides were measured at a constant peptide-to-lipid mass ratio (see Figures 6A and B, S9 and S10, and Table S9). Most of the peptides gave signals between 90 and $140 \mathrm{ppm}$, indicating a surface or slightly tilted orientation, while a few peptides gave larger chemical shifts indicating more inserted peptides. Another series with explicitly high P/L ratios of 1/20-25 was also examined (see Figures 6C and D, S11 and S12, and Table S10). Here, all peptides gave ${ }^{15} \mathrm{~N}$ chemical shifts between 135 and 170 ppm (see Table S10), indicating more tilted or inserted helices.

\section{DISCUSSION}

In this study we have mainly investigated the effect of charge and length of amphipathic a-helical peptides on their membrane activity. We will discuss first the length dependence, and then also the effect of hydrophobic residues, types of residues on the C-terminus of the peptides, and other factors influencing the leakage of model membranes.

\section{Length and charge}

We have recently shown a marked length-dependent activity of KIA peptides, which correlates with the thickness of the membrane used: only those peptides that are able to span the lipid bilayer or are longer than the hydrophobic thickness showed leakage of vesicles. ${ }^{31}$ KIA peptides have a sequence based on the heptameric repeat KIAGKIA, which represents 
approximately two turns of an $\alpha$-helix. This design provides a regular amphiphilic helical wheel for all peptides (Figure 1), with almost the same polar sector size, hydrophobic moment, mean hydrophobicity and charge density (charge per amino acid) for all peptides in the series. However, the net charge increases with length (Table 1), and it has previously been shown that for peptides of the same length, higher charge can lead to more active peptides. ${ }^{10}$ Therefore, in the previous study it could not be completely excluded that the charge, rather than the length, was involved in the differential activity found for the KIA peptides. ${ }^{31}$

Here, we designed new series of peptides with different lengths but with constant charge. Since KIA19 and KIA21 were found to be highly active, and have a charge of +7 , we designed peptides with lengths between 14 and 28 amino acids, all carrying a constant charge of +7 . We clearly observe the same length dependence for the two new series of peptides, as for the old KIA series with varying charge. In MIC for different bacteria, for hemolysis, and for leakage, it is always the case that peptides need a certain minimum length - which is different for different bacteria and for different model membranes - to be active, and this length is the same for peptides with varying charge and peptides with the same charge. Thus, we can conclude that the short KIA peptides are not inactive because of their reduced charge compared to the longer active peptides, because the short KIKA and KIA(7) peptides have the same charge as KIA21 and are still inactive. This observation clearly shows that the membrane activity of these KIA type peptides is determined by the length of the peptide and not by its total charge.

Another question that could not be answered in the previous study was, if the short peptides are intrinsically inactive, or would be active if the membrane would be thin enough so they could span it. Here, we were able to obtain charged DMoPG lipids with short acyl chains, and could prepare DMoPC/DMoPG (1:1) vesicles, with a hydrophobic thickness of $19.2 \AA,^{74}$ and measure leakage. As seen in Figure 4, the short peptides with 14 or 15 amino acids are indeed active and induce leakage in these thin membranes.

\section{Influence of hydrophobicity and Gly residues}

In the new series, all peptides had a charge of +7 , whereas the KIA peptides had a charge varying from +5 to +9 . Therefore, in the new series the shorter peptides ( $<19$ amino acids) must have a higher charge density, while the longer peptides ( $>21$ amino acids) must have a reduced charge density, and consequently some changes in the amino acid sequence were necessary. Since amino acid replacements also lead to other changes in peptide properties, we designed two 
different series of KIA-related peptides. In the KIA(7) series, we kept the same set of amino acids as in the KIA peptides (i.e. Lys, Ile, Ala, Gly), and replaced Lys with Ala for the long peptides, while for the short peptides Ile was replaced with Lys. This first series conserved the Gly positions of the KIA series. In the KIXA series, for the longer peptides (called KISA) Lys was replaced with Ser, a more polar residue than Ala, in order to keep the amphipathicity. For the shorter peptides (called KIKA), Gly were replaced with Lys. This series conserved the Ile positions of the KIA series.

Gly is the most common amino acid in $\mathrm{AMPs}^{75}$ and has been implied to have important functional relevance. ${ }^{10,76}$ Comparing the three series KIA, KIA(7) and KIXA, we can now examine the role of Gly. The hydrophobic residues are also important for the amphipathic character of AMPs, and the total hydrophobicity has been shown to be important for antimicrobial activity, too. ${ }^{10,37,77}$ According to $\mathrm{CD}$, all peptides are unstructured in aqueous solution, and they all form proper $\alpha$-helices in the presence of membranes (Table S1), except for the shortest KIA(7) peptides. KIA(7)14 exhibits a mostly random coil spectrum with a minimum around $199 \mathrm{~nm}$, similar to that found in solution. KIA(7)15 and KIA(7)17 also clearly have a lower helicity than the other peptides, with a minimum around $206 \mathrm{~nm}$ (Figure 2). These short peptides with 14-17 amino acids have an exceptionally high charge density, e.g. in KIA(7)14 half the positions carry a positive charge. They also contain two Gly residues, which are known to be helix-breakers. In addition, compared with KIA and KIXA peptides, they have fewer large and hydrophobic Ile residues. These particular peptides are thus very polar and also very flexible, so it seems that they simply do not bind to the membrane as strongly as the other peptides, and KIA(7)14 does not bind at all. Therefore, KIA(7) peptides with 14-17 amino acids are less active than would be expected just from their length, compared with the KIA and KIXA peptides.

Interestingly, the KIKA peptides with 14-17 amino acids are fully helical. They also have a total charge of +7 , but they do not contain Gly. Instead, they carry the more hydrophobic Ile residues, which seem to stabilize the additional helicity in the membrane bound state. The original KIA peptides with 14-17 amino acids also show helical CD spectra, even though they contain two Gly, but they are less charged and more hydrophobic (having Ile where KIA(7) carry Lys), so it seems that the combination of high charge and Gly residues makes the short KIA(7) peptides non-binding and therefore also non-helical. These short KIA(7) peptides are indeed inactive in the MIC and hemolysis assays. On the other hand, the short KIKA peptides are as 
helical as the corresponding KIA peptides, and show the same threshold length in the MIC assay, and a very similar hemolysis and leakage.

\section{Leakage}

In the leakage assay, we had previously shown that the KIA peptides had a lengthdependent activity with a very distinct threshold. This is here also found for the KIA(7) and KIXA peptides. The threshold fits very well with the experimentally determined hydrophobic thickness of the model membranes. DMoPC/DMoPG membranes have a hydrophobic thickness of $19.2 \AA,^{74}$ and even the shortest peptide, with an estimated length of $21 \AA$, is active. POPC/POPG membranes have a reported hydrophobic thickness of 27.1 or $27.8 \AA \AA^{78,79}$ and the theoretical length of the shortest active peptides, KIA17 or KIKA17, is $25.5 \AA$, which fits nicely to the membrane thickness. In the thicker DErPC/DErPG membranes with a hydrophobic width of $34.4 \AA$, only the longer peptides with at least 24 amino acids (corresponding to $36 \AA$ ) lead to leakage, as also shown previously. ${ }^{31}$ These observations are compelling evidence that the peptides must span the membranes, for example as expected in a transmembrane pore, to be active.

We can also note that it is easier to induce leakage in thinner membranes. In DMoPC/DMoPG, even the shortest peptides gives $100 \%$ leakage at $\mathrm{P} / \mathrm{L}=1: 100$, whereas in $\mathrm{DErPC} / \mathrm{DErPG}$ the longest peptides does not give full leakage even at $\mathrm{P} / \mathrm{L}=1: 12$. Therefore, the very sharp threshold length is more obvious in POPC/POPG than in DErPC/DErPG, but we would expect a clear threshold also in the thicker membranes at even higher P/L.

Comparing POPC/POPG and POPE/POPG, it can be noted that peptides induce more leakage in $\mathrm{PC} / \mathrm{PG}$ than $\mathrm{PE} / \mathrm{PG}$ at a given $\mathrm{P} / \mathrm{L}$. This was previously also found for other peptides and can be related to the difference in spontaneous lipid curvature between PE and PG. ${ }^{80}$ It was found that peptides and proteins can more easily insert into lipid systems with a positive spontaneous curvature, like lyso-lipids, than into lipid systems with a negative spontaneous curvature, like PE, and this can explain these effects. ${ }^{63,73}$ However, both POPC/POPG and POPE/POPG show the same threshold length, i.e. peptides shorter than 17 amino acids induce no leakage even at high concentration.

\section{Influence of a charged C-terminus}


In the MIC, hemolysis and leakage assays, in general longer peptides are more active than shorter, but in some cases it is seen that a longer peptide is less active than the next shorter peptide of the series. For example, KIA(7)22 is less active than KIA21 against $S$. aureus (Table 2), KISA22 is less active than KIA21 in several cases (Table 3); KIA26 and KISA26 give less hemolysis than KIA24 and KISA24, respectively (Figure 3); KIA19 gives less leakage in POPE/POPG than KIA17, and KIA26 and KISA26 give less leakage in DErPC/DErPG at $\mathrm{P} / \mathrm{L}=1 / 14$ than KIA24 and KISA24, respectively (Figure 4). (At lower P/L, the leakage differences are more obvious, as seen in Tables $\mathbf{S 7}$ and S8). In all these cases we can see a pattern: the less active peptide carries a positively charged side chain at the C-terminus, whereas the shorter and more active peptide have a more hydrophobic C-terminal Ile-Ala sequence. This shows that increasing the positive charges does not necessarily make an AMP more active.

This observation also allows us to propose a possible model for the mechanism of pore formation: It is clear from the leakage assay that the helices must be long enough to span the hydrophobic part of the membrane to form a transmembrane pore. The amphipathic peptides initially bind to the membrane in a flat orientation on the bilayer surface, with the hydrophobic face pointing down into the membrane, and the charged polar face pointing towards the aqueous phase (Figure 1). Next, an equilibrium is established between the surface bound peptides and a population of the inserted, transmembrane peptides. There is a high energetic barrier between the two states, because charged residues must get inserted into the membrane interior and completely cross the bilayer to switch from the surface bound state to the pore state. For thicker membrane, this energetic barrier is higher, so that it is harder for the peptides to insert and form a pore in DErPC/DErPG than in POPC/POPG, while in DMoPC/DMoPG pore formation is even easier.

We have previously shown using SSNMR that KIA21 (also called MSI-103) is oriented in a lipid bilayer such that the uncharged C-terminus (ending with Ile-Ala and an uncharged amidated C-terminus) is more deeply embedded in the membrane than the charged N-terminus (with a positive charge on the free amino-terminus plus the N-terminal Lys). Namely, in DMPC at $\mathrm{P} / \mathrm{L}=1 / 50$ we determined a tilt angle between the helix axis and the membrane normal of around $125^{\circ} .{ }^{81}$ This corresponds to an angle between the helix axis and the membrane plane of $35^{\circ}$, meaning that the peptide is already partly inserted with its $\mathrm{C}$-terminus into the hydrophobic core of the membrane. PGLa, which like KIA21 has an amidated C-terminus and has a Leu at the C-terminal position, has the same orientation as KIA21 in DMPC, whereas magainin 2, which has charges at both termini, lies flat on the membrane surface in the same lipid. ${ }^{24-26,62,63,82}$ 
If we now place a charged Lys onto the N-terminus of KIA21, this leads to an additional energetic barrier to insert this charge into the membrane, and we can expect that for such a peptide it is less likely that a pore will form. This is also indeed what we observe here, namely that the KIA type peptides ending with a Lys are less membrane-active than their shorter analogues ending with Ile-Ala. We can thus propose that the peptides insert in the membrane by dipping the more hydrophobic C-terminus first into the membrane, and that adding some additional hydrophobicity to this terminus should facilitate pore formation, whereas adding some charge here impedes insertion and pore formation. This hypothetical model is illustrated in Figure 7. Additional investigations will be needed to confirm this hypothesis.

\section{Peptide orientation}

The peptide orientation in lipid bilayers was monitored using solid-state ${ }^{15} \mathrm{~N}-\mathrm{NMR}$ in several lipid systems. For $\alpha$-helical peptides, the orientation can be estimated from the chemical shift, and almost all our peptides are shown by $\mathrm{CD}$ to be fully helical in membranes. Only KIA(7)14 remains unfolded, and $\operatorname{KIA}(7) 15$ and $\operatorname{KIA}(7) 17$ show less helicity than the other peptides. For KIA(7)14 and partly also for KIA(7)15, we see in ${ }^{15} \mathrm{~N}-\mathrm{NMR}$ chemical shifts around the isotropic value, so ${ }^{15} \mathrm{~N}-\mathrm{NMR}$ cannot be used to obtain information about the orientation in the membrane of these peptides that are not properly bound to the membrane. For all the other peptides, however, we can readily estimate the orientation in the membrane. In DMoPC/DMoPG and POPC/POPG, the same lipids as used for leakage assays, all KIXA and KIA(7) peptides are oriented flat on the membrane surface (Figure 5A-D). Almost all peptides give a high degree of leakage in these lipid systems, and since the helices in a pore are assumed to be in a transmembrane orientation, we would expect a signal at around $200 \mathrm{ppm}$ for these peptides. This is not, however, observed in the NMR data. Obviously, leakage can already occur even if only a small proportion of peptides are inserted in the membrane to form pores, but NMR reveals the orientation of the majority of peptides. Thus, it seems that only a small proportion of peptides are involved in the proposed pores responsible for the activity of the peptides.

DMoPC/DMoPG and POPC/POPG are two lipid systems with a negative spontaneous curvature, which is known to promote the surface-bound state and disfavor peptide insertion. ${ }^{63,73,81}$ In DMPC, a lipid with a small positive spontaneous curvature, it has been shown that it is easier for peptides to tilt into the membrane and to reach a transmembrane orientation, compared to POPC. ${ }^{63,73,81}$ Here, in DMPC at a constant mass ratio (P/L between 1/41 and 1/72), 
all peptides are found to lie almost flat in the membrane, except for KIA21 that gives an unusually broad line (Figure $\mathbf{5 E}$ and $\mathbf{F}$ ). The chemical shifts are generally a little bit higher than in $\mathrm{POPC} / \mathrm{POPG}$ or $\mathrm{DMoPC} / \mathrm{DMoPG}$, showing that the peptides might be tilted slightly deeper into the membrane (Table S9), but there is no large effect.

Lyso-lipids have a strong positive spontaneous curvature, which has been shown to promote the insertion of peptides into membranes. ${ }^{72,81,83}$ KIA peptides were found to be strongly inserted in DMPC/lyso-MPC (2/1), with the shortest peptides tilted the most. ${ }^{72}$ When studying the $\mathrm{KIA}(7)$ and KIXA peptides in this lipid system at a constant peptide-to-lipid mass ratio (P/L between $1 / 41$ and 1/72), we find that they are much less inserted in this lipid system than the corresponding KIA peptides (Figure 6A and B). For KIA(7) the chemical shifts are in the range 100-130 ppm, and for KIXA they are 95-125 ppm. There is no clear trend of chemical shifts as a function of length. While these chemical shift values are higher, and thus indicate that peptides are more tilted than in DMoPC/DMoPG, POPC/POPG or DMPC, it is still far from the values of 140-170 ppm found for KIA peptides in DMPC/lyso-MPC (2/1), where also a clear trend was seen with higher chemical shifts for the shorter peptides, which would be expected from a mismatch-dependent tilt. ${ }^{72}$

It thus seems that original KIA peptides insert more readily into membranes than the other two new series that we conceived here. For these shorter peptides with a length of 14-17 amino acids, the charge is higher than for the original KIA analogues. It is conceivable that the higher charge makes it harder for these peptides to insert and form oligomeric pores, in which the peptides approach each other closely, leading to electrostatic repulsion between the positively charged helices. However, the longer peptides with 22-28 amino acids have a lower charge and a lower charge density in the KIA(7) or KIXA series than in the KIA series and they also show less insertion, which does not fit the charge repulsion theory.

When the KIA(7) and KIXA peptides were studied in DMPC/lyso-MPC (2/1) at a higher concentration, using $\mathrm{P} / \mathrm{L}$ ratios between $1 / 20$ to $1 / 24$, larger chemical shifts between 135 and 173 ppm were observed by ${ }^{15} \mathrm{~N}-\mathrm{NMR}$, which correspond to inserted peptides (Figure 6C and $\mathbf{D}$ and Table S10). Compared to the original KIA peptides, there is a difference in the distribution of chemical shifts. For the KIA peptides, the most inserted orientation was found for the shortest peptides, or in other words the tilt from an upright position was larger for the longer peptides, and this was interpreted as a mismatch dependent tilt needed to reduce the hydrophobic mismatch. ${ }^{72}$ For the KIA(7) and KIXA peptides, however, the largest chemical shifts (and thus the most 
inserted orientation) was found for the longest peptides (Table S10), while the shorter peptides were only partly inserted. This behavior does not follow the hydrophobic mismatch hypothesis. It thus seems that only the KIA peptides, with a constant charge density, behave similar throughout their series, which made it possible to identify a clear hydrophobic mismatch-dependent tilt. The other two new series, in which all peptides have the same total charge (but shorter peptides have a much higher charge density than the longer ones), show a different insertion behavior for short and for long peptides. The shorter KIXA peptides are more tilted than the corresponding KIA(7) peptides. Further detailed investigations are needed to understand this behavior in detail, but we can conclude that all three series of peptides are able to get inserted into membranes with a high positive spontaneous curvature at a high peptide concentration.

\section{Conclusions}

To conclude, we have shown using three series of amphipathic peptides of different lengths, that their antimicrobial, hemolytic and vesicle leakage activity is strongly dependent on the length of the helix, whereas the charge is not a crucial factor. Peptides are active when they are long enough to span the hydrophobic width of the membrane. Even very short peptides with only 14 amino acids are active in very thin DMoPC/DMoPG model membranes, but they show no biological activity against bacteria or erythrocytes. We may thus conclude that the thickness of biological membranes can be estimated from the minimum length of peptides that are active against them. We also find that the mechanism of action of our KIA-type peptides involves initially a slight tilt of the more hydrophobic C-terminus into the membrane, followed at higher concentration by a flip and assembly into a fully inserted transmembrane pore complex. This pore formation is favored by thin membranes, by a positive spontaneous curvature of the lipids, and by a hydrophobic sequence at the C-terminus of the peptides.

\section{ACKNOWLEDGMENTS}

We thank Andrea Eisele and Kerstin Scheubeck for help with peptide synthesis, Siegmar Roth and Bianca Posselt for help with CD measurements, and Markus Schmitt for help with the NMR infrastructure. 


\section{SUPPORTING INFORMATION}

12 figures with additional leakage diagrams and NMR spectra, and 10 additional tables are found in the Supporting Information. 
REFERENCES

(1) Koczulla, A. R., and Bals, R. (2003) Antimicrobial peptides: current status and therapeutic potential. Drugs 63, 389-406.

(2) Guani-Guerra, E., Santos-Mendoza, T., Lugo-Reyes, S. O., and Teran, L. M. (2010) Antimicrobial peptides: general overview and clinical implications in human health and disease. Clin. Immunol. 135, 1-11.

(3) Brogden, K. A. (2005) Antimicrobial peptides: pore formers or metabolic inhibitors in bacteria? Nat. Rev. Microbiol. 3, 238-250.

(4) Pinheiro da Silva, F., and Machado, M. C. (2012) Antimicrobial peptides: clinical relevance and therapeutic implications. Peptides 36, 308-314.

(5) Saberwal, G., and Nagaraj, R. (1994) Cell-lytic and antibacterial peptides that act by perturbing the barrier function of membranes: facets of their conformational features, structure-function correlations and membrane-perturbing abilities. Biochim. Biophys. Acta 1197, 109-131.

(6) Fillion, M., Voyer, N., and Auger, M. (2014) Membrane interactions of amphiphilic peptides with antimicrobial potential: a solid-state NMR study. In Advances in Biological Solid-State NMR: Proteins and Membrane-Active Peptides (Separovic, F., and Naito, A., Eds.), pp 200-213, The Royal Society of Chemistry, London.

(7) Gordon, Y. J., Romanowski, E. G., and McDermott, A. M. (2005) A review of antimicrobial peptides and their therapeutic potential as anti-infective drugs. Curr. Eye Res. 30, 505-515.

(8) Bulet, P., Stocklin, R., and Menin, L. (2004) Anti-microbial peptides: from invertebrates to vertebrates. Immunol. Rev. 198, 169-184.

(9) Yeaman, M. R., and Yount, N. Y. (2003) Mechanisms of antimicrobial peptide action and resistance. Pharmacol. Rev. 55, 27-55.

(10) Zelezetsky, I., and Tossi, A. (2006) Alpha-helical antimicrobial peptides. Using a sequence template to guide structure-activity relationship studies. Biochim. Biophys. Acta $1758,1436-1449$.

(11) Hancock, R. E., and Lehrer, R. (1998) Cationic peptides: a new source of antibiotics. Trends Biotechnol 16, 82-88.

(12) Powers, J. P., and Hancock, R. E. (2003) The relationship between peptide structure and antibacterial activity. Peptides 24, 1681-1691.

(13) Huang, Y., Huang, J., and Chen, Y. (2010) Alpha-helical cationic antimicrobial peptides: relationships of structure and function. Protein \& cell 1, 143-152.

(14) Bahar, A. A., and Ren, D. (2013) Antimicrobial peptides. Pharmaceuticals (Basel) 6, 1543-1575.

(15) Maloy, W. L., and Kari, U. P. (1995) Structure-activity studies on magainins and other host-defense peptides. Biopolymers 37, 105-122.

(16) Soravia, E., Martini, G., and Zasloff, M. (1988) Antimicrobial properties of peptides from Xenopus granular gland secretions. FEBS Lett. 228, 337-340.

(17) Epand, R. F., Maloy, W. L., Ramamoorthy, A., and Epand, R. M. (2010) Probing the "charge cluster mechanism" in amphipathic helical cationic antimicrobial peptides. Biochemistry 49, 4076-4084.

(18) Strandberg, E., Tiltak, D., Ieronimo, M., Kanithasen, N., Wadhwani, P., and Ulrich, A. S. (2007) Influence of C-terminal amidation on the antimicrobial and hemolytic activities of cationic $\alpha$-helical peptides. Pure Appl. Chem. 79, 717-728. 
(19) Bechinger, B. (1997) Structure and functions of channel-forming peptides: Magainins, cecropins, melittin and alamethicin. J. Membr. Biol. 156, 197-211.

(20) Matsuzaki, K., Murase, O., and Miyajima, K. (1995) Kinetics of pore formation by an antimicrobial peptide, magainin 2, in phospholipid bilayers. Biochemistry 34, 12553 12559.

(21) Matsuzaki, K., Mitani, Y., Akada, K. Y., Murase, O., Yoneyama, S., Zasloff, M., and Miyajima, K. (1998) Mechanism of synergism between antimicrobial peptides magainin 2 and PGLa. Biochemistry 37, 15144-15153.

(22) Yang, L., Weiss, T. M., Lehrer, R. I., and Huang, H. W. (2000) Crystallization of antimicrobial pores in membranes: Magainin and protegrin. Biophys. J. 79, 2002-2009.

(23) Bechinger, B. (2010) Membrane association and pore formation by alpha-helical peptides. Adv. Exp. Med. Biol. 677, 24-30.

(24) Strandberg, E., Wadhwani, P., Tremouilhac, P., Dürr, U. H. N., and Ulrich, A. S. (2006) Solid-state NMR analysis of the PGLa peptide orientation in DMPC bilayers: structural fidelity of ${ }^{2} \mathrm{H}$-labels versus high sensitivity of ${ }^{19}$ F-NMR. Biophys. J. 90, 1676-1686.

(25) Tremouilhac, P., Strandberg, E., Wadhwani, P., and Ulrich, A. S. (2006) Conditions affecting the re-alignment of the antimicrobial peptide PGLa in membranes as monitored by solid state ${ }^{2}$ H-NMR. Biochim. Biophys. Acta 1758, 1330-1342.

(26) Tremouilhac, P., Strandberg, E., Wadhwani, P., and Ulrich, A. S. (2006) Synergistic transmembrane alignment of the antimicrobial heterodimer PGLa/magainin. J. Biol. Chem. 281, 32089-32094.

(27) Huang, H. W. (2006) Molecular mechanism of antimicrobial peptides: the origin of cooperativity. Biochim. Biophys. Acta 1758, 1292-1302.

(28) Matsuzaki, K. (1998) Magainins as paradigm for the mode of action of pore forming polypeptides. Biochim. Biophys. Acta 1376, 391-400.

(29) Oren, Z., and Shai, Y. (1998) Mode of action of linear amphipathic $\alpha$-helical antimicrobial peptides. Biopolymers 47, 451-463.

(30) Baumann, G., and Mueller, P. (1974) A molecular model of membrane excitability. $J$. Supramol. Struct. 2, 538-557.

(31) Grau-Campistany, A., Strandberg, E., Wadhwani, P., Reichert, J., Bürck, J., Rabanal, F., and Ulrich, A. S. (2015) Hydrophobic mismatch demonstrated for membranolytic peptides, and their use as molecular rulers to measure bilayer thickness in native cells. Sci. Rep. 5, 9388.

(32) Hall, K., Lee, T. H., and Aguilar, M. I. (2011) The role of electrostatic interactions in the membrane binding of melittin. Journal of molecular recognition : JMR 24, 108-118.

(33) Sitaram, N., and Nagaraj, R. (1999) Interaction of antimicrobial peptides with biological and model membranes: structural and charge requirements for activity. Biochim. Biophys. Acta 1462, 29-54.

(34) Dathe, M., and Wieprecht, T. (1999) Structural features of helical antimicrobial peptides: their potential to modulate activity on model membranes and biological cells. Biochim. Biophys. Acta 1462, 71-87.

(35) Hong, S. Y., Park, T. G., and Lee, K. H. (2001) The effect of charge increase on the specificity and activity of a short antimicrobial peptide. Peptides 22, 1669-1674.

(36) Blondelle, S. E., and Houghten, R. A. (1992) Design of model amphipathic peptides having potent antimicrobial activities. Biochemistry 31, 12688-12694.

(37) Dathe, M., Wieprecht, T., Nikolenko, H., Handel, L., Maloy, W. L., MacDonald, D. L., Beyermann, M., and Bienert, M. (1997) Hydrophobicity, hydrophobic moment and angle 
subtended by charged residues modulate antibacterial and haemolytic activity of amphipathic helical peptides. FEBS Lett. 403, 208-212.

(38) Sitaram, N., Chandy, M., Pillai, V. N., and Nagaraj, R. (1992) Change of glutamic acid to lysine in a 13-residue antibacterial and hemolytic peptide results in enhanced antibacterial activity without increase in hemolytic activity. Antimicrob. Agents Chemother. 36, 24682472.

(39) Matsuzaki, K., Nakamura, A., Murase, O., Sugishita, K., Fujii, N., and Miyajima, K. (1997) Modulation of magainin 2-lipid bilayer interactions by peptide charge. Biochemistry 36, 2104-2111.

(40) Dathe, M., Nikolenko, H., Meyer, J., Beyermann, M., and Bienert, M. (2001) Optimization of the antimicrobial activity of magainin peptides by modification of charge. FEBS Lett 501, 146-150.

(41) Jiang, Z., Vasil, A. I., Hale, J. D., Hancock, R. E. W., Vasil, M. L., and Hodges, R. S. (2008) Effects of net charge and the number of positively charged residues on the biological activity of amphipathic $\alpha$-helical cationic antimicrobial peptides. Peptide Science 90, 369-383.

(42) Carpino, L. A., and Han, G. Y. (1972) 9-Fluorenylmethoxycarbonyl amino-protecting group. J. Org. Chem. 37, 3404-3409.

(43) Fields, G. B., and Noble, R. L. (1990) Solid-phase peptide synthesis utilizing 9fluorenylmethoxycarbonyl amino acids. Int. J. Pept. Protein Res. 35, 161-214.

(44) Strandberg, E., Kanithasen, N., Bürck, J., Wadhwani, P., Tiltak, D., Zwernemann, O., and Ulrich, A. S. (2008) Solid state NMR analysis comparing the designer-made antibiotic MSI-103 with its parent peptide PGLa in lipid bilayers. Biochemistry 47, 2601-2616.

(45) Wadhwani, P., Strandberg, E., Heidenreich, N., Bürck, J., Fanghänel, S., and Ulrich, A. S. (2012) Self-assembly of flexible $\beta$-strands into immobile amyloid-like $\beta$-sheets in membranes as revealed by solid-state ${ }^{19}$ F NMR. J. Am. Chem. Soc. 134, 6512-6515.

(46) Wadhwani, P., Strandberg, E., van den Berg, J., Mink, C., Bürck, J., Ciriello, R., and Ulrich, A. S. (2014) Dynamical structure of the short multifunctional peptide BP100 in membranes. Biochim. Biophys. Acta 1838, 940-949.

(47) Johnson, W. C. (1999) Analyzing protein circular dichroism spectra for accurate secondary structures. Proteins 35, 307-312.

(48) Sreerama, N., Venyaminov, S. Y., and Woody, R. W. (2000) Estimation of protein secondary structure from circular dichroism spectra: inclusion of denatured proteins with native proteins in the analysis. Anal. Biochem. 287, 243-251.

(49) Provencher, S. W., and Glockner, J. (1981) Estimation of globular protein secondary structure from circular dichroism. Biochemistry 20, 33-37.

(50) van Stokkum, I. H., Spoelder, H. J., Bloemendal, M., van Grondelle, R., and Groen, F. C. (1990) Estimation of protein secondary structure and error analysis from circular dichroism spectra. Anal. Biochem. 191, 110-118.

(51) Sreerama, N., Venyaminov, S. Y., and Woody, R. W. (1999) Estimation of the number of $\alpha$-helical and $\beta$-strand segments in proteins using circular dichroism spectroscopy. Protein Sci. 8, 370-380.

(52) Sreerama, N., and Woody, R. W. (1993) A self-consistent method for the analysis of protein secondary structure from circular dichroism. Anal. Biochem. 209, 32-44.

(53) Whitmore, L., and Wallace, B. A. (2004) DICHROWEB, an online server for protein secondary structure analyses from circular dichroism spectroscopic data. Nucleic Acids Res. 32, W668-673. 
(54) Lobley, A., Whitmore, L., and Wallace, B. A. (2002) DICHROWEB: an interactive website for the analysis of protein secondary structure from circular dichroism spectra. Bioinformatics 18, 211-212.

(55) Ruden, S., Hilpert, K., Berditsch, M., Wadhwani, P., and Ulrich, A. S. (2009) Synergistic interaction between silver nanoparticles and membrane-permeabilizing antimicrobial peptides. Antimicrob. Agents Chemother. 53, 3538-3540.

(56) Duzgunes, N., and Wilschut, J. (1993) Fusion assays monitoring intermixing of aqueous contents. Methods Enzymol. 220, 3-14.

(57) Steinbrecher, T., Prock, S., Reichert, J., Wadhwani, P., Zimpfer, B., Bürck, J., Berditsch, M., Elstner, M., and Ulrich, A. S. (2012) Peptide-lipid interactions of the stress-response peptide TisB that induces bacterial persistence. Biophys. J. 103, 1460-1469.

(58) Mayer, L. D., Hope, M. J., and Cullis, P. R. (1986) Vesicles of variable sizes produced by a rapid extrusion procedure. Biochim. Biophys. Acta 858, 161-168.

(59) Ellens, H., Bentz, J., and Szoka, F. C. (1985) $\mathrm{H}^{+}-$and $\mathrm{Ca}^{2+}$-induced fusion and destabilization of liposomes. Biochemistry 24, 3099-3106.

(60) Grage, S. L., Strandberg, E., Wadhwani, P., Esteban-Martin, S., Salgado, J., and Ulrich, A. S. (2012) Comparative analysis of the orientation of transmembrane peptides using solid-state ${ }^{2} \mathrm{H}$ - and ${ }^{15} \mathrm{~N}-\mathrm{NMR}$ : mobility matters. Eur. Biophys. J. 41, 475-482.

(61) Müller, S. D., De Angelis, A. A., Walther, T. H., Grage, S. L., Lange, C., Opella, S. J., and Ulrich, A. S. (2007) Structural characterization of the pore forming protein TatAd of the twin-arginine translocase in membranes by solid-state ${ }^{15} \mathrm{~N}-\mathrm{NMR}$. Biochim. Biophys. Acta 1768, 3071-3079.

(62) Glaser, R. W., Sachse, C., Dürr, U. H. N., Afonin, S., Wadhwani, P., Strandberg, E., and Ulrich, A. S. (2005) Concentration-dependent realignment of the antimicrobial peptide PGLa in lipid membranes observed by solid-state ${ }^{19}$ F-NMR. Biophys. J. 88, 3392-3397.

(63) Strandberg, E., Zerweck, J., Wadhwani, P., and Ulrich, A. S. (2013) Synergistic insertion of antimicrobial magainin-family peptides in membranes depends on the lipid spontaneous curvature. Biophys. J. 104, L9-11.

(64) Heinzmann, R., Grage, S. L., Schalck, C., Bürck, J., Banoczi, Z., Toke, O., and Ulrich, A. S. (2011) A kinked antimicrobial peptide from Bombina maxima. II. Behavior in phospholipid bilayers. Eur. Biophys. J. 40, 463-470.

(65) Walther, T. H., Grage, S. L., Roth, N., and Ulrich, A. S. (2010) Membrane alignment of the pore-forming component Tat $\mathrm{A}_{\mathrm{d}}$ of the twin-arginine translocase from Bacillus subtilis resolved by solid-state NMR spectroscopy. J. Am. Chem. Soc. 132, 15945-15956.

(66) Rance, M., and Byrd, R. A. (1983) Obtaining high-fidelity spin-1/2 powder spectra in anisotropic media - phase-cycled Hahn echo spectroscopy. J. Magn. Reson. 52, 221-240.

(67) Levitt, M. H., Suter, D., and Ernst, R. R. (1986) Spin dynamics and thermodynamics in solid-state NMR cross polarization. J. Chem. Phys. 84, 4243-4255.

(68) Fung, B. M., Khitrin, A. K., and Ermolaev, K. (2000) An improved broadband decoupling sequence for liquid crystals and solids. J. Magn. Reson. 142, 97-101.

(69) Raetz, C. R. H. (1978) Enzymology, genetics, and regulation of membrane phospholipid synthesis in Escherichia coli. Microbiol. Rev. 42, 614-659.

(70) Bechinger, B., Gierasch, L. M., Montal, M., Zasloff, M., and Opella, S. J. (1996) Orientations of helical peptides in membrane bilayers by solid state NMR spectroscopy. Solid State Nucl. Magn. Reson. 7, 185-191. 
(71) Marassi, F. M., Opella, S. J., Juvvadi, P., and Merrifield, R. B. (1999) Orientation of cecropin A helices in phospholipid bilayers determined by solid-state NMR spectroscopy. Biophys. J. 77, 3152-3155.

(72) Grau-Campistany, A., Strandberg, E., Wadhwani, P., Rabanal, F., and Ulrich, A. S. (2016) Extending the hydrophobic mismatch concept to amphiphilic membranolytic peptides. J. Phys. Chem. Lett. 7, 1116-1120.

(73) Strandberg, E., and Ulrich, A. S. (2015) AMPs and OMPs: Is the folding and bilayer insertion of $\beta$-stranded outer membrane proteins governed by the same biophysical principles as for $\alpha$-helical antimicrobial peptides? Biochim. Biophys. Acta 1848, $1944-$ 1954.

(74) Marsh, D. (2008) Energetics of hydrophobic matching in lipid-protein interactions. Biophys. J. 94, 3996-4013.

(75) Wang, Z., and Wang, G. S. (2004) APD: the Antimicrobial Peptide Database. Nucleic Acids Res. 32, D590-D592.

(76) Carlier, L., Joanne, P., Khemtemourian, L., Lacombe, C., Nicolas, P., El Amri, C., and Lequin, O. (2015) Investigating the role of GXXXG motifs in helical folding and selfassociation of plasticins, Gly/Leu-rich antimicrobial peptides. Biophys. Chem. 196, 40-52.

(77) Wieprecht, T., Dathe, M., Beyermann, M., Krause, E., Maloy, W. L., MacDonald, D. L., and Bienert, M. (1997) Peptide hydrophobicity controls the activity and selectivity of magainin 2 amide in interaction with membranes. Biochemistry 36, 6124-6132.

(78) Pan, J., Heberle, F. A., Tristram-Nagle, S., Szymanski, M., Koepfinger, M., Katsaras, J., and Kucerka, N. (2012) Molecular structures of fluid phase phosphatidylglycerol bilayers as determined by small angle neutron and X-ray scattering. Biochim. Biophys. Acta 1818, 2135-2148.

(79) Kucerka, N., Tristram-Nagle, S., and Nagle, J. F. (2005) Structure of fully hydrated fluid phase lipid bilayers with monounsaturated chains. J. Membr. Biol. 208, 193-202.

(80) Zerweck, J., Strandberg, E., Bürck, J., Reichert, J., Wadhwani, P., Kukharenko, O., and Ulrich, A. S. (2016) Homo- and heteromeric interaction strengths of the synergistic antimicrobial peptides PGLa and magainin 2 in membranes. Eur. Biophys. J. 45, 535-547.

(81) Strandberg, E., Tiltak, D., Ehni, S., Wadhwani, P., and Ulrich, A. S. (2012) Lipid shape is a key factor for membrane interactions of amphipathic helical peptides. Biochim. Biophys. Acta 1818, 1764-1776.

(82) Strandberg, E., Tremouilhac, P., Wadhwani, P., and Ulrich, A. S. (2009) Synergistic transmembrane insertion of the heterodimeric PGLa/magainin 2 complex studied by solidstate NMR. Biochim. Biophys. Acta 1788, 1667-1679.

(83) Zamora-Carreras, H., Strandberg, E., Mühlhäuser, P., Bürck, J., Wadhwani, P., Jiménez, M. Á., Bruix, M., and Ulrich, A. S. (2016) Alanine scan and ${ }^{2} \mathrm{H}$ NMR analysis of the membrane-active peptide BP100 point to a distinct carpet mechanism of action. Biochim. Biophys. Acta 1858 1328-1338. 


\section{TABLES}

Table 1. Peptide sequences. Original KIA peptides (with varying charge and length). KIA(7) peptides (with constant charge of +7 and varying length; Ile $\rightarrow$ Lys or Lys $\rightarrow$ Ala). KIXA peptides (with constant charge of +7 and varying length; Gly $\rightarrow$ Lys or Lys $\rightarrow$ Ser).

\begin{tabular}{|c|c|c|c|c|}
\hline Peptide & Sequence $^{\mathrm{a}}$ & Substitutions $^{\text {b }}$ & Charge & $\begin{array}{c}\text { Molecular } \\
\text { Weight } \\
\text { (g/mol) }\end{array}$ \\
\hline KIA14 & KIAGKIA KIAGKIA-NH & - & +5 & 1382 \\
\hline KIA15 & KIAGKIA KIAGKIA K-NH & - & +6 & 1510 \\
\hline KIA17 & KIAGKIA KIAGKIA KIA-NH & - & +6 & 1694 \\
\hline KIA19 & KIAGKIA KIAGKIA KIAGK-NH & - & +7 & 1879 \\
\hline KIA21 & KIAGKIA KIAGKIA KIAGKIA-NH & - & +7 & 2064 \\
\hline KIA22 & KIAGKIA KIAGKIA KIAGKIA K-NH & - & +8 & 2192 \\
\hline KIA24 & KIAGKIA KIAGKIA KIAGKIA KIA-NH & - & +8 & 2376 \\
\hline KIA26 & KIAGKIA KIAGKIA KIAGKIA KIAGK-NH & - & +9 & 2561 \\
\hline KIA28 & KIAGKIA KIAGKIA KIAGKIA KIAGKIA-NH & - & +9 & 2746 \\
\hline $\operatorname{KIA}(7) 14$ & KKAGKIA KKAGKIA-NH & $2 \times$ Ile $\rightarrow$ Lys & +7 & 1412 \\
\hline $\operatorname{KIA}(7) 15$ & KIAGKIA KKAGKIA K-NH & $\mathrm{Ile} \rightarrow$ Lys & +7 & 1525 \\
\hline $\operatorname{KIA}(7) 17$ & KIAGKIA KKAGKIA KIA-NH & $\mathrm{Ile} \rightarrow$ Lys & +7 & 1708 \\
\hline $\operatorname{KIA}(7) 22$ & KIAGKIA AIAGKIA KIAGKIA K-NH & Lys $\rightarrow$ Ala & +7 & 2134 \\
\hline $\operatorname{KIA}(7) 24$ & KIAGKIA AIAGKIA KIAGKIA KIA-NH & Lys $\rightarrow$ Ala & +7 & 2318 \\
\hline $\operatorname{KIA}(7) 26$ & KIAGKIA AIAGKIA KIAGAIA KIAGK-NH & $2 \times$ Lys $\rightarrow$ Ala & +7 & 2446 \\
\hline $\operatorname{KIA}(7) 28$ & KIAGKIA AIAGKIA KIAGAIA KIAGKIA-NH & $2 \times$ Lys $\rightarrow$ Ala & +7 & 2631 \\
\hline KIKA14 & KIAKKIA KIAKKIA-NH & $2 \times$ Gly $\rightarrow$ Lys & +7 & 1524 \\
\hline KIKA15 & KIAGKIA KIAKKIA $\mathrm{K}-\mathrm{NH}_{2}$ & Gly $\rightarrow$ Lys & +7 & 1582 \\
\hline KIKA17 & KIAGKIA KIAKKIA KIA-NH & Gly $\rightarrow$ Lys & +7 & 1766 \\
\hline KISA22 & KIAGKIA SIAGKIA KIAGKIA K-NH & Lys $\rightarrow$ Ser & +7 & 2150 \\
\hline KISA24 & KIAGKIA SIAGKIA KIAGKIA KIA-NH & Lys $\rightarrow$ Ser & +7 & 2334 \\
\hline KISA26 & KIAGKIA SIAGKIA KIAGSIA KIAGK-NH & $2 \times$ Lys $\rightarrow$ Ser & +7 & 2478 \\
\hline KISA28 & KIAGKIA SIAGKIA KIAGSIA KIAGKIA-NH & $2 \times$ Lys $\rightarrow$ Ser & +7 & 2662 \\
\hline
\end{tabular}

${ }^{a}$ Ala-10 (marked in bold) was ${ }^{15} \mathrm{~N}$-labelled at the backbone amide in all peptides.

${ }^{\mathrm{b}}$ Substitutions compared to the corresponding KIA peptide (underlined in the sequences). 
Table 2. MIC values $(\mu \mathrm{g} / \mathrm{mL})$ for $\mathrm{KIA}(7)$ peptides in four different bacterial strains. Inactive peptides are marked in bold for each strain.

\begin{tabular}{|c|c|c|c|c|}
\hline \multirow[t]{2}{*}{ Peptide } & \multicolumn{2}{|c|}{ Gram negative } & \multicolumn{2}{|c|}{ Gram positive } \\
\hline & E. coli & P. aeruginosa & S. aureus & E. faecalis \\
\hline $\operatorname{KIA}(7) 14$ & $>256$ & $>256$ & $>256$ & $>1024$ \\
\hline $\operatorname{KIA}(7) 15$ & $>256$ & $>256$ & $>256$ & $>1024$ \\
\hline $\operatorname{KIA}(7) 17$ & $>256$ & $>256$ & $>256$ & $>1024$ \\
\hline KIA19 ${ }^{a}$ & 64 & 256 & $>256$ & $>1024$ \\
\hline KIA21 ${ }^{\mathrm{a}}$ & 4 & 64 & 16 & 1024 \\
\hline $\operatorname{KIA}(7) 22$ & 4 & 128 & 64 & 1024 \\
\hline $\operatorname{KIA}(7) 24$ & 4 & 64 & 8 & 64 \\
\hline $\operatorname{KIA}(7) 26$ & 4 & 32 & 8 & 32 \\
\hline $\operatorname{KIA}(7) 28$ & 8 & 64 & 16 & 16 \\
\hline
\end{tabular}

${ }^{a}$ KIA19 and KIA21 were measured anew together with the KIA(7) and KIXA peptides.

Table 3. MIC values $(\mu \mathrm{g} / \mathrm{mL})$ for KIXA peptides in four different bacterial strains. Inactive peptides are marked in bold for each strain.

\begin{tabular}{|c|c|c|c|c|}
\hline \multirow[t]{2}{*}{ Peptide } & \multicolumn{2}{|c|}{ Gram negative } & \multicolumn{2}{|c|}{ Gram positive } \\
\hline & E. coli & P. aeruginosa & S. aureus & E. faecalis \\
\hline KIKA14 & 256 & $>256$ & $>256$ & $>1024$ \\
\hline KIKA15 & $>256$ & $>256$ & $>256$ & $>1024$ \\
\hline KIKA17 & 16 & 128 & 256 & $>1024$ \\
\hline KIA19 ${ }^{a}$ & 64 & 256 & $>256$ & $>1024$ \\
\hline KIA2 ${ }^{a}$ & 4 & 64 & 16 & 1024 \\
\hline KISA22 & 8 & 256 & 128 & $>1024$ \\
\hline KISA24 & 4 & 64 & 8 & 128 \\
\hline KISA26 & 4 & 128 & 32 & 512 \\
\hline KISA28 & 4 & 128 & 8 & 32 \\
\hline
\end{tabular}

${ }^{a}$ KIA19 and KIA21 were measured anew together with the KIA(7) and KIXA peptides. 
Table 4. MIC values $(\mu \mathrm{g} / \mathrm{mL})$ for the original KIA peptides in four different bacterial strains. Inactive peptides are marked in bold for each strain. ${ }^{\mathrm{a}}$

\begin{tabular}{lcccc}
\hline Peptide & \multicolumn{2}{c}{ Gram negative } & \multicolumn{2}{c}{ Gram positive } \\
& E. coli & P. aeruginosa & S. aureus & E. faecalis \\
\hline KIA14 & $>\mathbf{2 5 6}$ & $\mathbf{2 5 6}$ & $>\mathbf{2 5 6}$ & $>\mathbf{1 0 2 4}$ \\
\hline KIA15 & $>\mathbf{2 5 6}$ & $\mathbf{2 5 6}$ & $>\mathbf{2 5 6}$ & $>\mathbf{1 0 2 4}$ \\
\hline KIA17 & 32 & $\mathbf{2 5 6}$ & $\mathbf{2 5 6}$ & $>\mathbf{1 0 2 4}$ \\
\hline KIA19 & 32 & $\mathbf{2 5 6}$ & $>\mathbf{2 5 6}$ & $\mathbf{1 0 2 4}$ \\
\hline KIA21 & 4 & 64 & 8 & $\mathbf{1 0 2 4}$ \\
\hline KIA22 & 4 & 32 & 16 & $\mathbf{1 0 2 4}$ \\
\hline KIA24 & 4 & 16 & 4 & 64 \\
\hline KIA26 & 4 & 16 & 8 & 64 \\
\hline KIA28 & 8 & 16 & 8 & 16 \\
\hline
\end{tabular}

${ }^{a}$ Results are taken from Ref. ${ }^{31}$ 


\section{FIGURES}

Figure 1. Helical wheels of the original MSI-103 peptide (KIA21), and of the shortest and the longest peptide within each of the three series (KIAn, KIA(7)n and KIXAn). The hydrophobic sector is shown in grey, the polar sector in white. Charged residues and termini are indicated. Boxed residues indicate changes compared to the corresponding KIA peptides of the same length.

KIAn
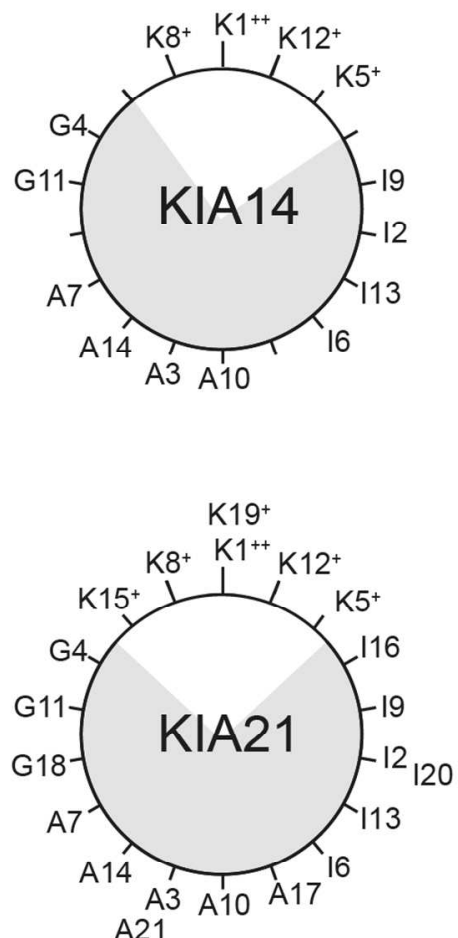

A21
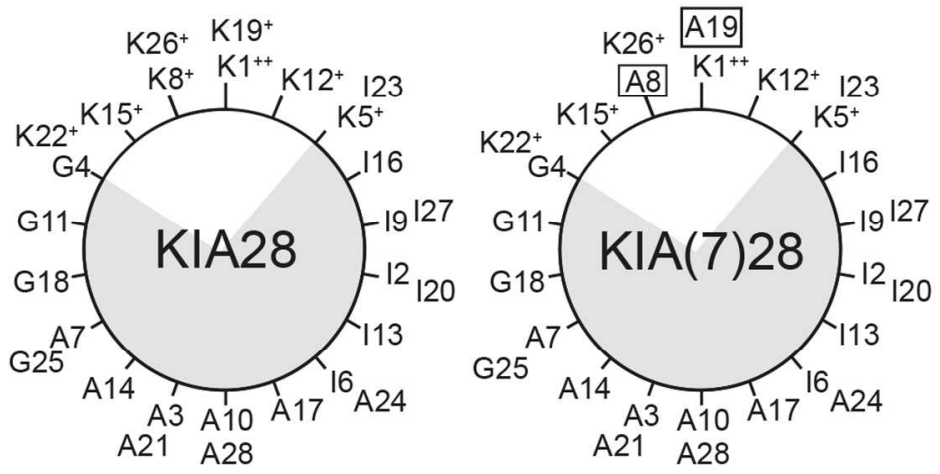

KIXAn
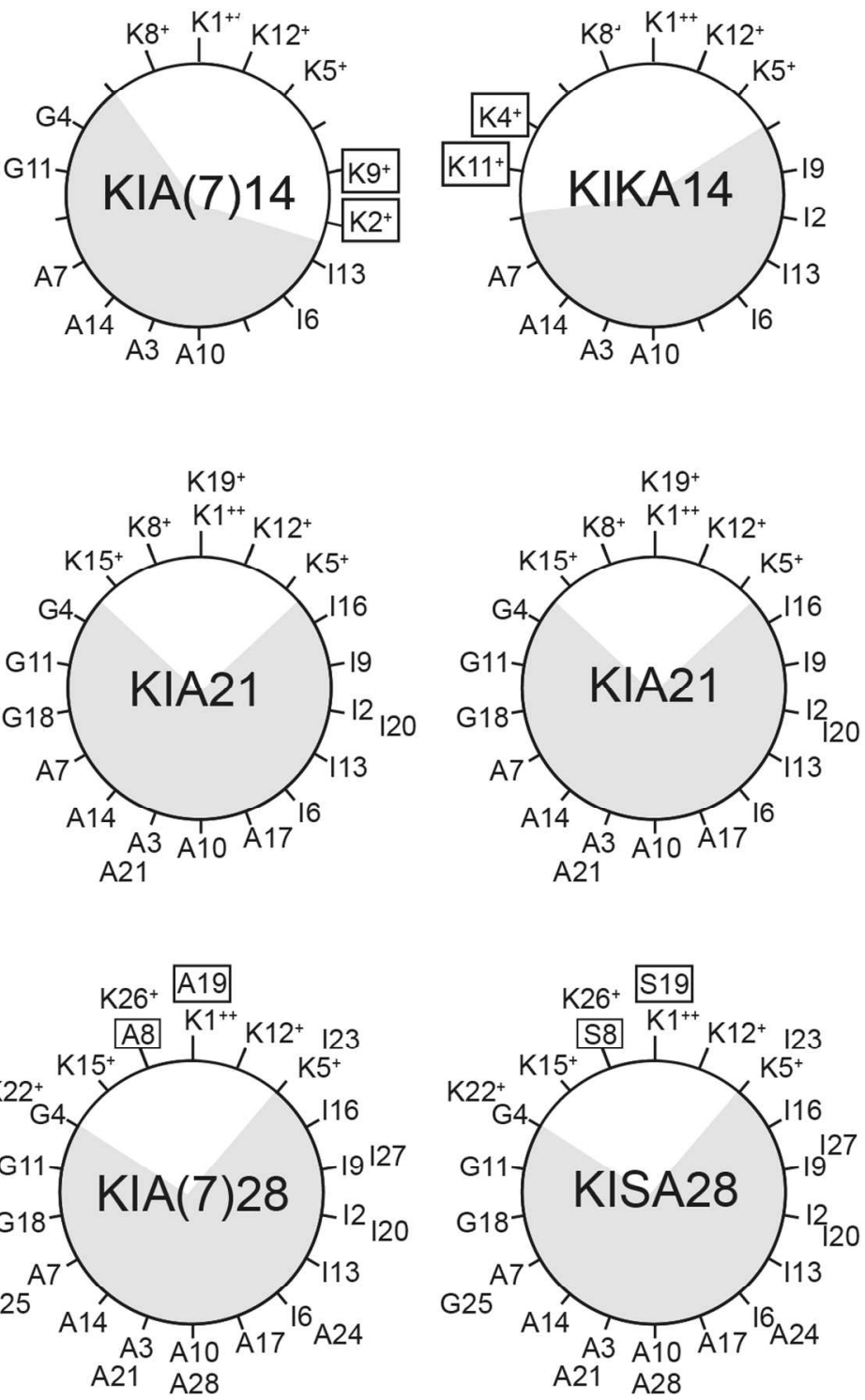
Figure 2. Circular dichroism spectra for $\operatorname{KIA}(7)(\mathrm{A}-\mathrm{B})$ and KIXA (C-D) peptides in phosphate buffer (corresponding to peptide concentrations of 34-60 $\mu \mathrm{M})(\mathrm{A}, \mathrm{C})$, or in the presence of DMPC/DMPG 3/1 small unilamellar vesicles at P/L near 1/55, and with a peptide concentration near $25 \mu \mathrm{M}(\mathrm{B}, \mathrm{D})$.
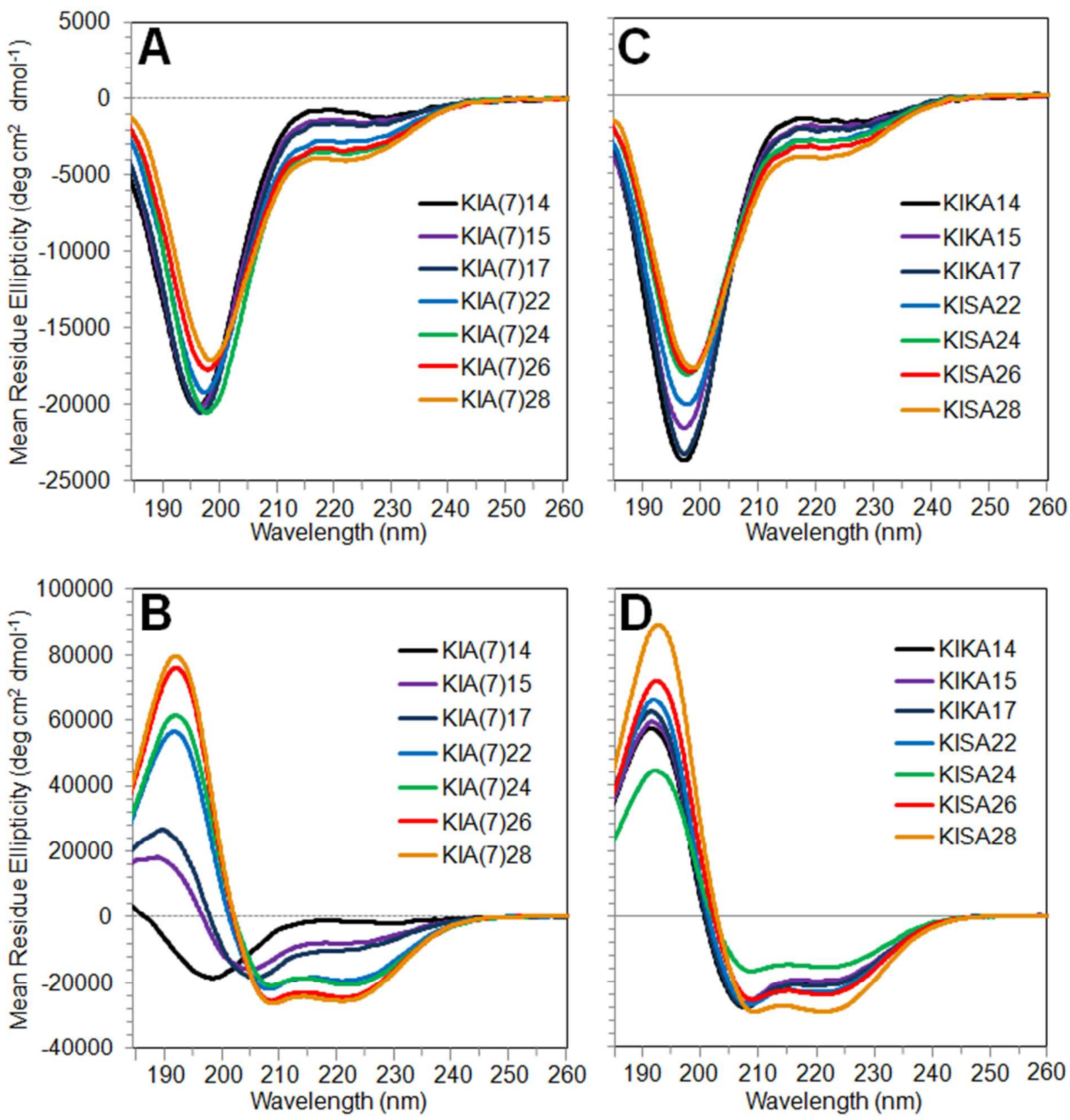
Figure 3. Hemolysis (in \%) of KIA (A-D), KIA(7) (E-H), and KIXA (I-L) peptides as a function of concentration $(8-512 \mu \mathrm{g} / \mathrm{mL})$. (KIA results are taken from ${ }^{31}$ ).
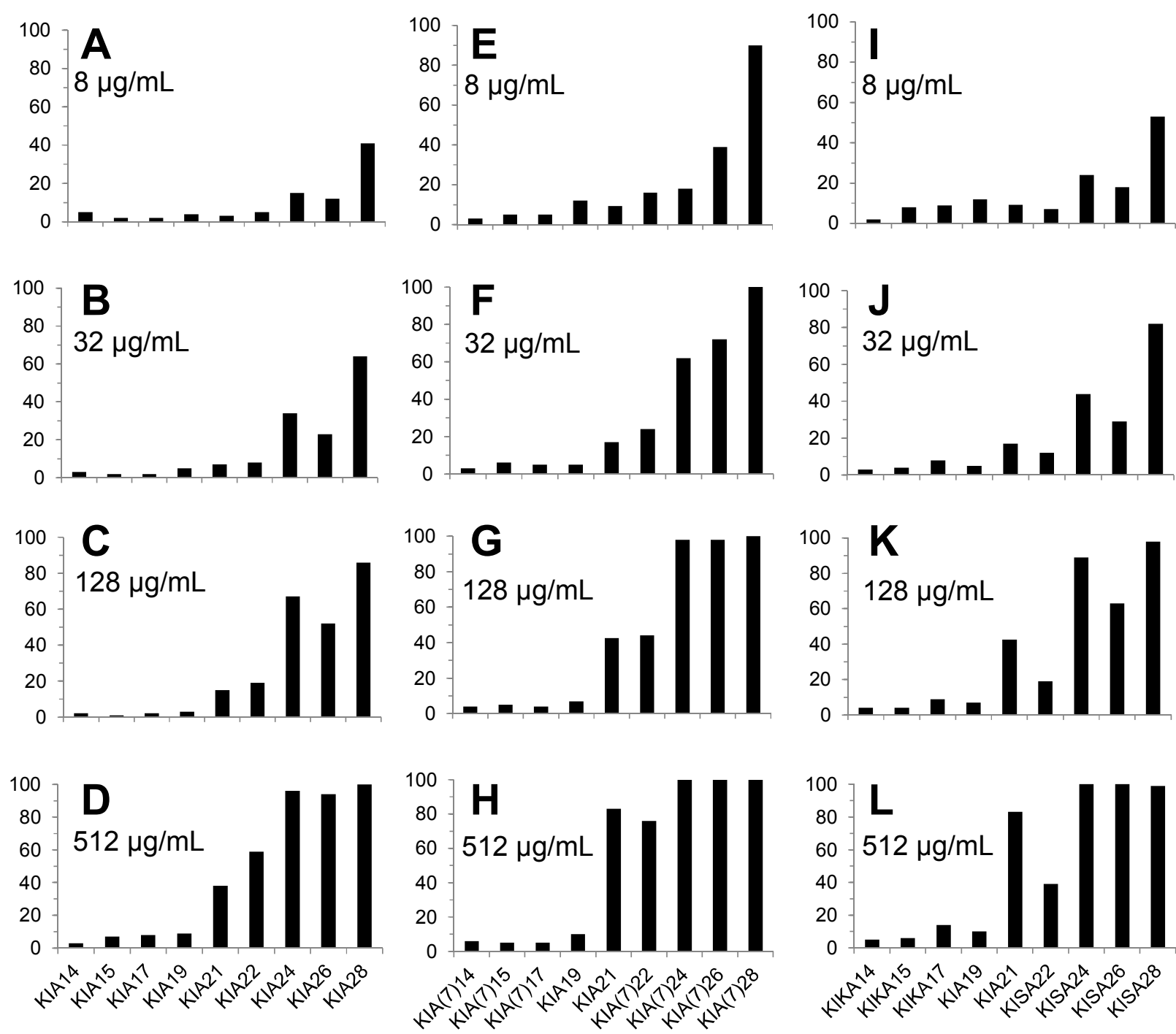
Figure 4. Leakage (in \%) induced by KIA (A-D), KIA(7) (E-H), and KIXA (I-L) peptides in DMoPC/DMoPG 1/1 (A, E, I), in POPC/POPG 1/1 (B, F, J), in POPE/POPG 1/1 (C, G, K) and in DErPC/DErPG 1/1 (D, H, L) vesicles. (KIA results in POPC/POPG and DErPC/DErPG are taken from ${ }^{31}$ ). The lipid concentration was $100 \mu \mathrm{M}$ and the peptide concentration $\approx 8 \mu \mathrm{M}$ giving $\mathrm{P} / \mathrm{L}=1 / 12.5-1 / 15$.
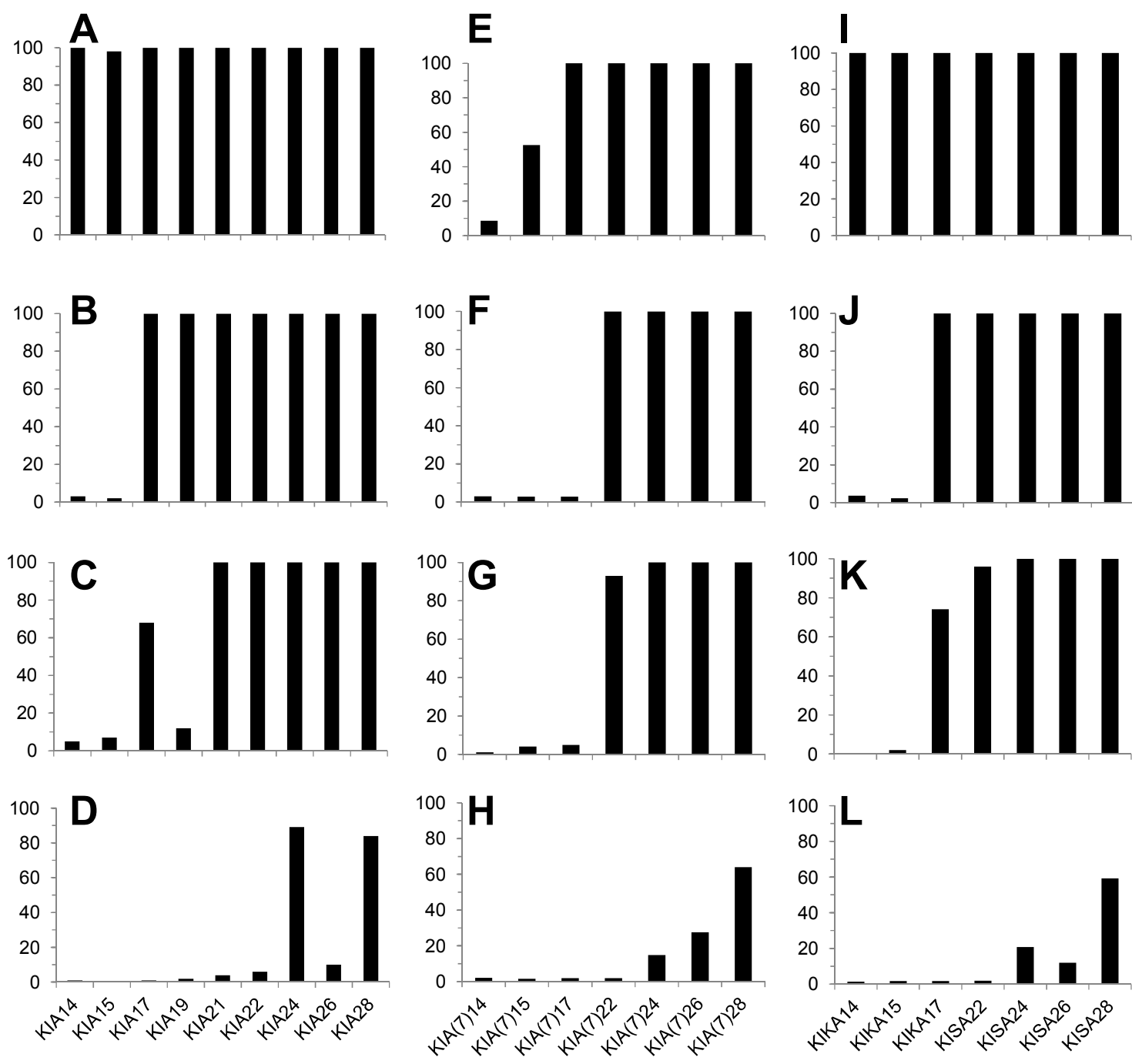
Figure 5. Solid-state ${ }^{15} \mathrm{~N}-\mathrm{NMR}$ spectra of $\operatorname{KIA}(7)$ (A, C and E) and KIXA (B, D and F) peptides at a constant peptide-to-lipid mass ratio (corresponding to $\mathrm{P} / \mathrm{L}=1 / 41$ to $1 / 72$ ) in POPC/POPG $1 / 1$ (A and B), in DMoPC/DMoPG 1/1 (C and D), and in DMPC (E and F). The black dotted line (at $90 \mathrm{ppm})$ indicates the typical position for surface-oriented peptides. KIA19 and KIA21 were measured only once but are added in all series as a comparison. (KIA19 and KIA21 data in DMPC are taken from ${ }^{31}$ ).

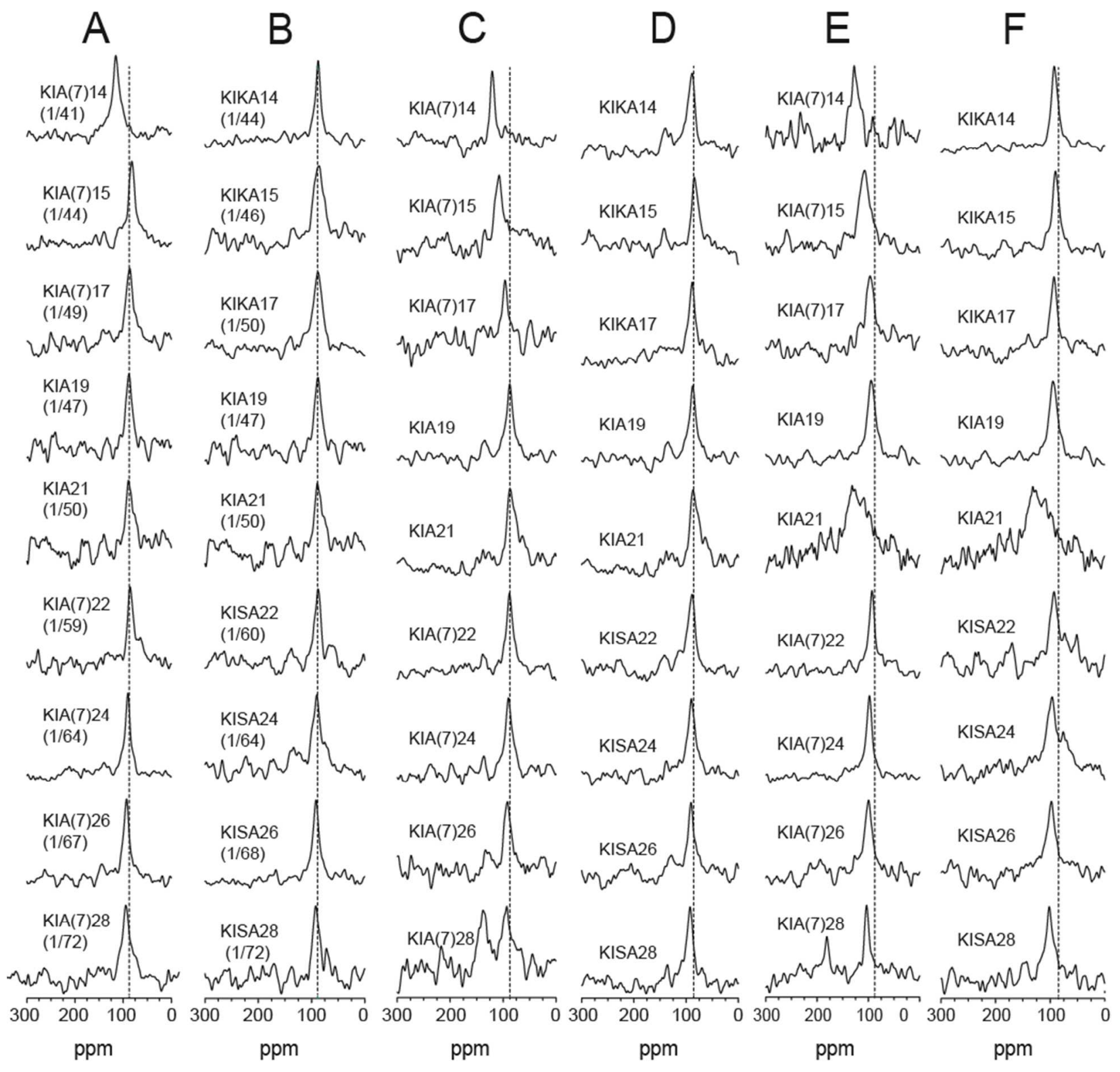


Figure 6. Solid-state ${ }^{15} \mathrm{~N}-\mathrm{NMR}$ spectra in DMPC/lyso-MPC (2/1). (A) KIA(7) series and (B) KIXA series of peptides at a constant peptide-to-lipid mass ratio; (C) KIA(7) peptides at $\mathrm{P} / \mathrm{L}=1 / 20-24$; (D) KIXA peptides at $\mathrm{P} / \mathrm{L}=1 / 20-24$. The dotted (90 ppm), dashed (138 ppm) and continuous (175 ppm) lines indicate the typical spectral positions for surface-oriented, tilted and inserted, peptides, respectively. (KIA19 and KIA21 data at low concentration are taken from ${ }^{31}$ ).

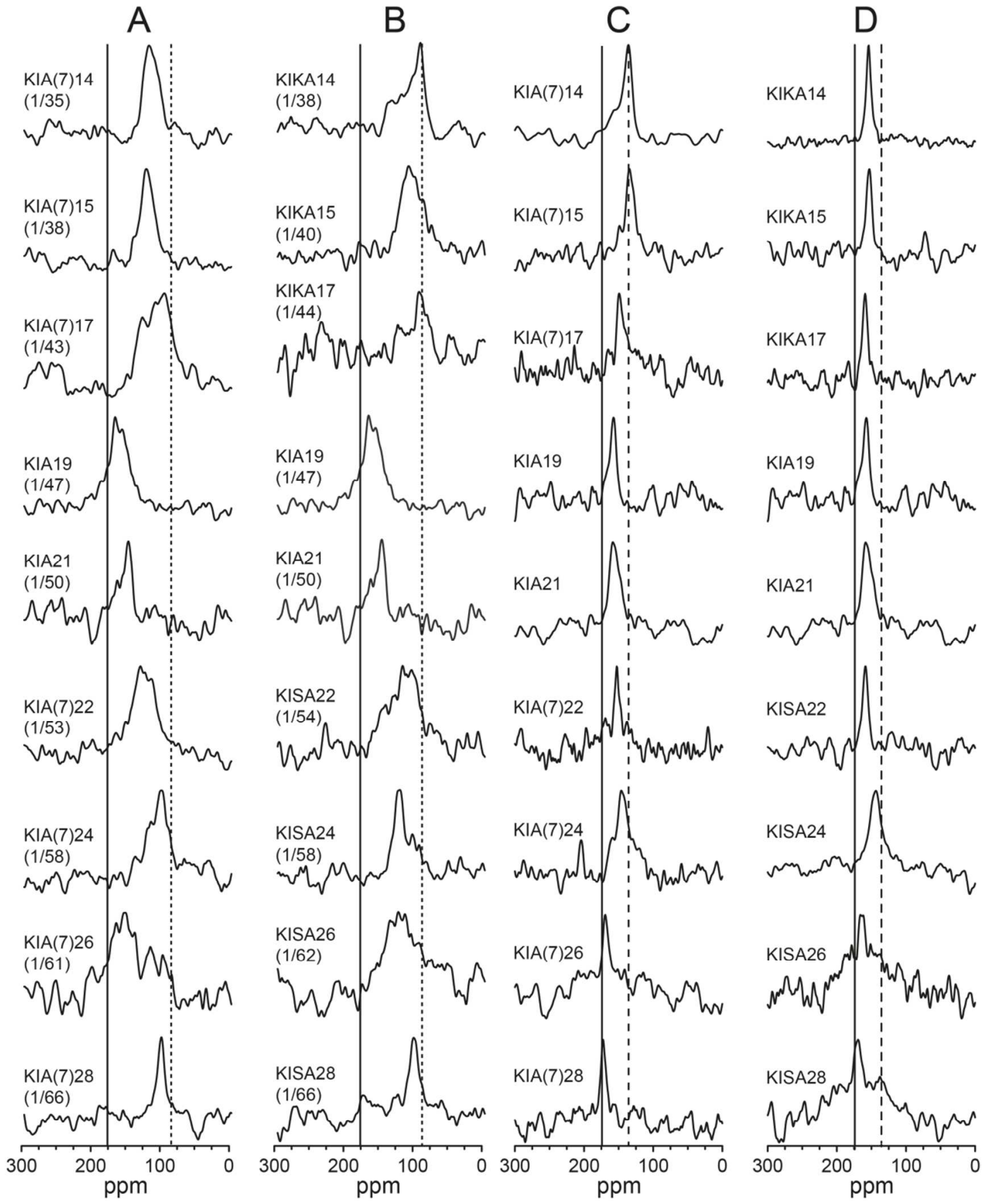


Figure 7. Hypothetical model of peptide insertion and pore formation. Peptides are represented by cylinders, where hydrophobic parts are yellow and polar parts blue; the hydrophobic core of the membrane is shown as a yellow box. All KIA peptides carry a free N-terminal Lys, which provides two positive charges. (A) Peptides like KIA21 (= MSI-103) have a hydrophobic Ile-Ala segment on their amidated C-terminus. They bind to the membrane surface with a slight tilt angle such that the C-terminus lies deeper in the membrane. ${ }^{81}$ This hydrophobic C-terminus makes it easier to insert even further into/across the lipid bilayer and form a transmembrane pore. (B) KIA peptide like KIA22 carry a charged Lys at the C-terminus. They will likely lie flat in the membrane, like magainin. ${ }^{63}$ Their charged C-terminus makes it harder to insert into/across the membrane and form a pore, as observed here in the activity assays (MIC, hemolysis, vesicle leakage).

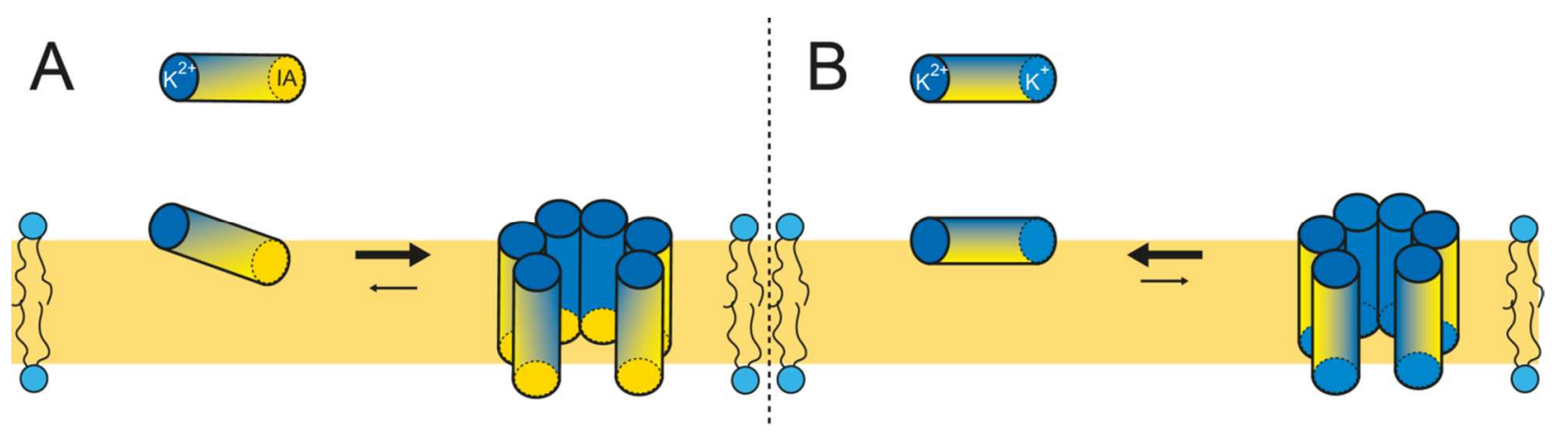


For Table of Contents Use Only

\title{
Influence of length and charge on the activity of $\alpha$-helical amphipathic antimicrobial peptides
}

\author{
Marie-Claude Gagnon, Erik Strandberg, Ariadna Grau-Campistany, Parvesh Wadhwani, Johannes \\ Reichert, Jochen Bürck, Francesc Rabanal, Michèle Auger, Jean-François Paquin, Anne S. Ulrich
}

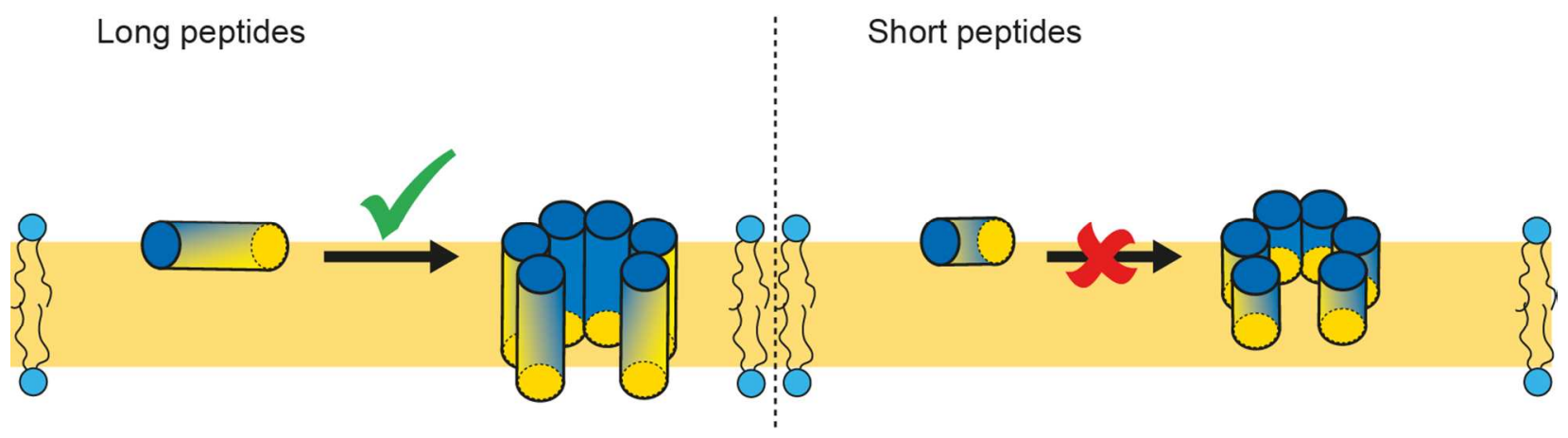

